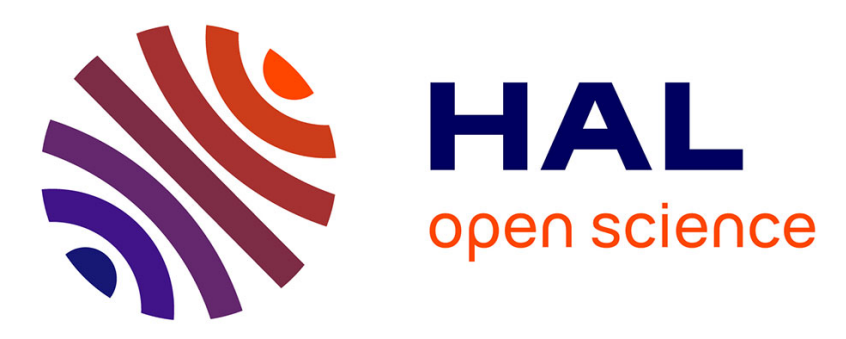

\title{
Structure of Hydrated Kaolinite Edge Surfaces: DFT Results and Further Development of the ClayFF Classical Force Field with Metal-O-H Angle Bending Terms
}

Maxime Pouvreau, Jeffery A. Greathouse, Randall T. Cygan, Andrey G. Kalinichev

\section{To cite this version:}

Maxime Pouvreau, Jeffery A. Greathouse, Randall T. Cygan, Andrey G. Kalinichev. Structure of Hydrated Kaolinite Edge Surfaces: DFT Results and Further Development of the ClayFF Classical Force Field with Metal-O-H Angle Bending Terms. J.Phys.Chem.C, 2019, 123 (18), pp.11628-11638. 10.1021/acs.jpcc.9b00514 . hal-02317376

\section{HAL Id: hal-02317376 \\ https://hal.science/hal-02317376}

Submitted on 15 Feb 2022

HAL is a multi-disciplinary open access archive for the deposit and dissemination of scientific research documents, whether they are published or not. The documents may come from teaching and research institutions in France or abroad, or from public or private research centers.
L'archive ouverte pluridisciplinaire HAL, est destinée au dépôt et à la diffusion de documents scientifiques de niveau recherche, publiés ou non, émanant des établissements d'enseignement et de recherche français ou étrangers, des laboratoires publics ou privés. 


\section{Structure of Hydrated Kaolinite Edge Surfaces:}

\section{DFT Results and Further Development of the ClayFF Classical Force Field with Metal-O-H Angle Bending Terms}

Maxime Pouvreau, ${ }^{\dagger}$ Jeffery A. Greathouse, ${ }^{*}{ }^{\S}$ Randall T. Cygan ${ }^{\S}$, Andrey G. Kalinichev ${ }^{*}, \dagger$

†Laboratoire SUBATECH (UMR 6457 - Institut Mines-Télécom Atlantique, Université de Nantes, CNRS/IN2P3), 44307 Nantes, France

Department of Chemistry, Washington State University, Pullman, Washington 99164, USA

${ }^{\S}$ Geochemistry Department, Sandia National Laboratories, P.O Box 5800, MS 0754, Albuquerque, NM, 87185-0754, USA

*Corresponding Authors: jagreat@ sandia.gov

kalinich@subatech.in2p3.fr 


\section{ABSTRACT}

Toward the development of classical force fields for the accurate modeling of clay mineral-water systems, we have extended the use of metal-O-H (M-O-H) angle bending terms to describe surface Si-O-H bending for hydrated kaolinite edge structures. Kaolinite, comprised of linked octahedral $\mathrm{Al}$ and tetrahedral $\mathrm{Si}$ sheets, provides a rigorous test by combining aluminol and silanol groups with water molecules in hydrated edge structures. Periodic density functional theory and classical force fields were used with molecular dynamics to evaluate structure, dynamics, hydrogen bonding, and power spectra for deriving optimum bending force constants and optimal equilibrium angles. Cleavage energies derived from density functional theory molecular dynamics (DFT-MD) calculations indicate the relative stability of both $\mathrm{AC}_{1}$ and $\mathrm{AC}_{2}$ edge terminations of kaolinite where $\mathrm{Si}-\mathrm{OH}$ and $\mathrm{Al}-\left(\mathrm{OH}_{2}\right)$ or $\mathrm{Si}-\mathrm{OH}, \mathrm{Al}-\mathrm{OH}$, and $\mathrm{Al}-$ $\left(\mathrm{OH}_{2}\right)$ groups exist, respectively. Although not examined in this study, the new Si-O-H angle bending parameter should allow for improved modeling of hydroxylated surfaces of silica minerals such as quartz and cristobalite, as well as amorphous silica-based surfaces and potentially those of other silicate and aluminosilicate phases. 


\section{INTRODUCTION}

Atomistic simulations of aluminosilicate clay minerals and related layered phases have seen widespread use over the past twenty years, providing molecular-level insight into structural and dynamic properties of their hydrated interlayers and interfaces for a wide variety of applications in fundamental science and engineering, including spectroscopic and structural characterization of clay interlayers and aqueous interfaces, ${ }^{1-7}$ clay swelling phenomena and fossil energy extraction, ${ }^{8-10}$ clay-polymer nanocomposites, ${ }^{11-16}$ fate and transport of contaminants in the subsurface, ${ }^{17-20}$ and underground disposal of waste products from energy production. ${ }^{21-25}$ Many of the aforementioned simulation studies were performed at the classical level of theory using approximate energy expressions in the form of force fields (FFs). Large compositional and structural diversity of clays require large system sizes and long timescales accessible with FF-based classical molecular dynamics (CMD) simulations to allow for the realistic computation of macroscopic observables such as structural parameters, transport properties, and adsorption properties. The continued use and success of clay-based FFs to predict experimentally accessible properties are due in large part to the development of robust, transferrable FFs specifically for layered minerals and their fluid interfaces. ${ }^{26-31}$

In the present study we focus on ClayFF, ${ }^{29}$ which consists primarily of nonbonded electrostatic and van der Waals interactions, allowing for efficient simulation while still maintaining natural flexibility within the clay layers. Framework flexibility is particularly important for accurately simulating molecular momentum transfer at the mineral-fluid interface. ClayFF has been used extensively to simulate bulk properties of clays and the interaction of fluids at their basal surfaces and interlayers. However, the extension of ClayFF to accurately model crystal edge surfaces requires a new parameterization of surface hydroxyl groups either already present in the crystal or satisfying dangling bonds as a result of mineral cleavage or growth/dissolution processes. In particular, M-O-H angle bending parameters 
(where $\mathrm{M}$ is a layer metal atom or cation such as $\mathrm{Si}, \mathrm{Al}$, or $\mathrm{Mg}$ ) were not fully developed in the original parameter set. ${ }^{29}$ At a minimum, an $\mathrm{M}-\mathrm{O}-\mathrm{H}$ angle term prevents instabilities resulting from local structural disorder. ${ }^{32-35}$ The strong hydrogen bonds observed between hydroxyl groups at the edge surface by ab initio simulations in clay minerals ${ }^{36}$ likely contribute to the overall cohesion of these surfaces. Similar to force field improvements that result in stronger M-O interactions,${ }^{37}$ the parameters that restrain the orientation of the edge hydroxyl groups act to mechanically stabilize the interfacial hydrogen bonds, thus preventing unphysical dissociation of surface hydroxyl groups into the fluid phase and allowing to realistically model finite-size clay nanoparticles in classical atomistic simulations.

We have previously developed ClayFF-compatible $\mathrm{M}-\mathrm{O}-\mathrm{H}$ angle bending terms for $\mathrm{Mg}$ and $\mathrm{Al}$ atoms in octahedral coordination, guided by periodic quantum calculations using density functional theory (DFT) on endmember layered phases brucite, $\mathrm{Mg}(\mathrm{OH})_{2}$, and gibbsite, $\mathrm{Al}(\mathrm{OH})_{3} \cdot{ }^{38,39}$ In this work, we continue the development of $\mathrm{M}-\mathrm{O}-\mathrm{H}$ angle bending terms for ClayFF- hereafter referred to as ClayFF-MOH—specifically for silanol ( $\mathrm{Si}-\mathrm{O}-\mathrm{H})$ groups that exist at cleaved surfaces of clay minerals containing siloxane sheets. In the evolution of our previous work, the structural models used for Si-O-H parametrization are based on the neutral endmember clay mineral kaolinite.

Kaolinite, $\mathrm{Al}_{2} \mathrm{Si}_{2} \mathrm{O}_{5}(\mathrm{OH})_{4}$, occurs extensively in numerous soil and sedimentary environments, and has significant impact in many geochemical, environmental, and technological applications, primarily due to its occurrence and stability under a broad range of temperature, pressure, and chemical conditions. ${ }^{40}$ Like all phyllosilicate clay minerals, kaolinite is characterized by a polymerized structure of $\mathrm{SiO}_{4}$ tetrahedra (T) occurring as a siloxane sheet, which, in the case of kaolinite, is linked to a single sheet of $\mathrm{AlO}_{4}(\mathrm{OH})_{2}$ octahedra $(\mathrm{O})$ to form a repetitive TO layered structure. Only two of the three available octahedral sites in the Al sheet are occupied thereby leading to the dioctahedral designation. ${ }^{41}$ The coordination environment 
of each $\mathrm{Al}$ includes one inner hydroxyl group and three hydroxyl groups on the basal surface. Typically exhibiting ideal stoichiometry and with limited impurities, kaolinite has no net layer charge. Hydrogen bonds between basal hydroxyl groups of the $\mathrm{O}$ sheet and the basal siloxane oxygens of the $\mathrm{T}$ sheet result in stable TO-TO interactions that ultimately create the book-like crystal habit extending along the $c$-axis. ${ }^{41}$ The hexagonal-based atomic ring structures of the $\mathrm{Si}(\mathrm{T})$ and $\mathrm{Al}(\mathrm{O})$ sheets result in hexagonally-shaped macroscopic crystals with terminating edge structures that are the main focus of this computational study.

It has been understood for quite some time that edge sites contribute strongly to kaolinite surface area and charge development. ${ }^{42}$ Several periodic DFT studies have examined adsorption and chemical properties of cleaved edge surfaces of kaolinite. Kremleva et al. ${ }^{43}$ modeled the adsorption of $\mathrm{UO}_{2}{ }^{2+}$ ions on the (010) edge surface in the presence of a monolayer of water. Their preliminary calculations determined that the most stable protonation state at the edge consists of one $\mathrm{Al}$ atom per unit cell coordinated by one $\mathrm{OH}$ group and one $\mathrm{OH}_{2}$ group, ${ }^{43}$ which is consistent with the model edge surface used in the present study. The relative stability of various terminations of edge surfaces exposed to water have been studied by Liu and coworkers using DFT-MD simulations, initially to determine stable coordination environments for edge $\mathrm{Al}$ and $\mathrm{Si}$ atoms, ${ }^{44}$ as well as surface $\mathrm{pKa}$ values. ${ }^{45}$ These studies provide insight into the local coordination environment at hydrated kaolinite edges under different $\mathrm{pH}$ conditions, which will aid in the construction of model surfaces for FF simulations of kaolinite-water interfaces. Although the surface chemistry must remain fixed during FF simulations, interfacial properties at larger scales can be modeled at different solution or $\mathrm{pH}$ conditions based on the DFTpredicted protonation states.

Our methodology in developing and testing Si-O-H angle bending parameters is similar to our previous work on octahedrally-coordinated metal atoms (Al-O-H and Mg-O-H) ${ }^{38,39}$ The new Si-O-H angle bending parameters are derived for kaolinite edges based on comparisons of 
structural and vibrational properties of edge silanol groups with the results of DFT-MD simulations. Additional validation is provided through detailed comparisons of hydrogen bonding properties at hydrated kaolinite edges, demonstrating the compatibility of multiple M$\mathrm{O}-\mathrm{H}$ angle terms in the same energy expression.

\section{STRUCTURAL MODELS AND EDGE TERMINATIONS}

The unit cell of kaolinite $\mathrm{Al}_{2} \mathrm{Si}_{2} \mathrm{O}_{5}(\mathrm{OH})_{4}$ crystal was constructed based on the $\mathrm{X}$-ray diffraction data of Neder et al., which provides cell parameters of $5.15 \times 8.94 \times 7.40 \AA^{3}, \alpha=$ $91.69^{\circ}, \gamma=104.61^{\circ}, \beta=89.82^{\circ}{ }^{46}$ The positions of hydrogen atoms and the orientations of the structural $\mathrm{OH}$ groups were further verified using neutron powder diffraction data. ${ }^{47}$ The edge models of kaolinite were built from this unit cell by cleaving the bulk crystal along the corresponding crystallographic plane.

The most commonly observed kaolinite edge surfaces are (010), (110) and the (11̄0). ${ }^{48}$ The $(010)$ edge model was built from a $2 \times 1 \times 2$ supercell cleaved along the corresponding planes. To build the (110) and (110) edge models, the unit cell was doubled along the [001] direction and multiplied along the direction orthogonal to the cleavage plane by a factor to obtain the same bulk formula as the (010) edge model (i.e., $\left.\mathrm{Al}_{8} \mathrm{Si}_{8} \mathrm{O}_{20}(\mathrm{OH})_{16}\right)$. The cleavage planes were slightly translated with respect to the crystal structure in order to minimize the number of dangling bonds, which revealed the (010) and (110) edge models as structurally equivalent and correspond to the AC chain type while the $(1 \overline{1} 0)$ surface corresponds to the B chain type. ${ }^{49}$ Both edge types have been featured in the published DFT studies of kaolinite edge structures. ${ }^{43-}$ ${ }^{45}$ The AC- and B-edge models and the bulk supercell were equilibrated using DFT-MD NVTensemble simulations (number of particles $N$, volume $V$, temperature $T=300 \mathrm{~K}$ ) and average energies were obtained from subsequent constant potential energy (E) NVE-ensemble 
simulations (Table 1). Reorientations of the hydroxyl groups were readily observed at this temperature, and sampling these various configurations leads to a more realistic estimation of the surface energy than the static approach.

DFT-MD snapshots of the AC- and B-edges are shown in Fig. 1. During equilibration, a water molecule is spontaneously desorbed from a B-edge Al site while all the AC-edge Al sites remain 6-coordinated. The cleavage energies per surface area are defined as:

$$
\Delta E_{\text {cleav }}=\frac{E_{\mathrm{edge}}-\left(E_{\mathrm{bulk}}+n E_{\mathrm{H} 2 \mathrm{O}, \mathrm{gas}}\right)}{A}
$$

where $E_{\text {edge }}, E_{\text {bulk }}$ and $E_{\mathrm{H} 2 \mathrm{O} \text {,gas }}$ are the DFT-MD average energies obtained, respectively, for the edge models, the bulk model, and an isolated water molecule in a $15 \times 15 \times 15 \AA^{3}$ box, and $A$ is the total surface area of the respective edge model.

Table 1. Energies of cleavage $\left(\Delta E_{\text {cleav }}\right)$ and water desorption $\left(\Delta E_{\text {desorp }}^{\mathrm{H} 2 \mathrm{O}}\right)$ for the two types of kaolinite edge surfaces, calculated as averages of total energies at $T=300 \mathrm{~K}$ from $N V E$-ensemble DFT-MD simulations. Refer to Fig. 1 for the corresponding snapshots.

\begin{tabular}{lcc}
\multicolumn{1}{c}{ Edge type } & $\begin{array}{c}\text { Edge surface area } \\
\left(\AA^{2}\right)\end{array}$ & $\begin{array}{c}\Delta E_{\text {cleav }} \\
\left(\mathrm{kcal}^{2} \mathrm{~mol}^{-1} . \AA^{-2}\right)\end{array}$ \\
$\mathrm{AC}^{[1]}$ & 295 & 0.032 \\
$\mathrm{~B}^{[2]}$ & 213 & 0.140 \\
Equivalent to (110) & \\
A water molecule is spontaneously desorbed during equilibration.
\end{tabular}

The dangling bonds were satisfied using chemi- or physi-sorption of $\mathrm{H}_{2} \mathrm{O}$ molecules in order to obtain bulk-like $\mathrm{AlO}_{6}$ and $\mathrm{SiO}_{4}$ coordinations, resulting in a zero net charge. In the periodic model, adjacent mineral slabs were separated by a $15 \AA$ vacuum region. The resulting $\mathrm{AC}_{1}$ surface was terminated by $\mathrm{SiOH}$ and $\mathrm{Al}(\mathrm{OH})\left(\mathrm{OH}_{2}\right)$ groups, and the resulting $\mathrm{AC}_{2}$ and $\mathrm{B}$ 
surfaces were terminated by $\mathrm{SiOH}$ and $\mathrm{Al}\left(\mathrm{OH}_{2}\right)$ groups. The cleavage energies of the $\mathrm{AC}$ - and B-edge models are, respectively, 0.032 and $0.140 \mathrm{kcal} \cdot \mathrm{mol}^{-1} \cdot \AA^{-2}$. Therefore, we selected the kaolinite AC-edge as a representative structural model. According to the free energy calculations of Liu et al. ${ }^{44}$, for a neutral model an $\mathrm{AC}_{2}$ surface - “(110)-2” in their paper-will consist of both 5- and 6-coordinated Al sites, while an $\mathrm{AC}_{1}$ surface-“(110)-1” in their paperessentially consists of 6 -coordinated $\mathrm{Al}$ sites. According to their $\mathrm{pKa}$ calculations, ${ }^{45}$ kaolinite edge surfaces consisting of $\mathrm{SiOH}$ and $\mathrm{Al}(\mathrm{OH})\left(\mathrm{OH}_{2}\right)$ forms are likely to exist in neutral or moderately acidic conditions, due to their respective $\mathrm{pKa}$ values of 6.9 and 5.7.

Two model sizes were considered for subsequent calculations. The preliminary static calculations and the DFT-MD simulations were based on a $2 \times 1 \times 2$ supercell, and the CMD simulations were based on a $4 \times 2 \times 4$ supercell. To represent the complexity of a mineral surface consisting of 5- and 6-coordinated $\mathrm{Al}$ sites with a certain spatial distribution, the size of the model needs to be sufficiently large, which is not the case of the $2 \times 1 \times 2$ supercell. Therefore, all $\mathrm{Al}$ atoms on the $\mathrm{AC}_{1}$ edge surface were coordinated by one $\mathrm{OH}$ group and one $\mathrm{OH}_{2}$ group.

AC edge / (010)

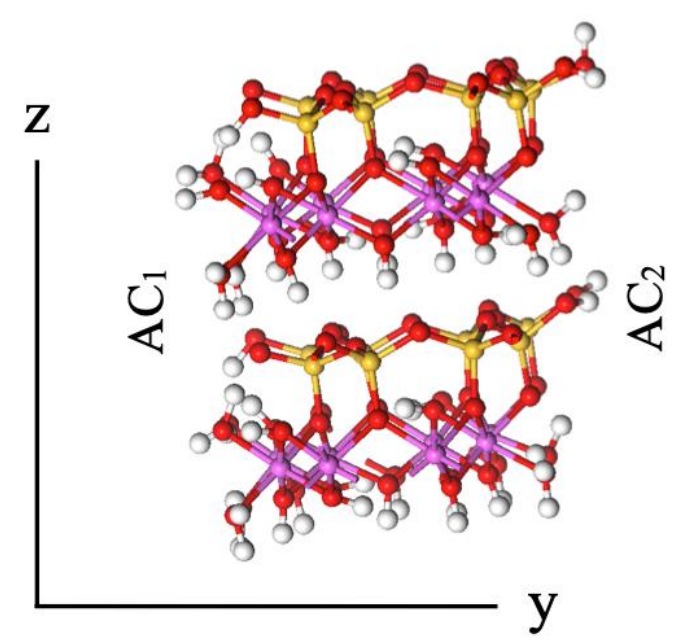

B edge / (11̄0)

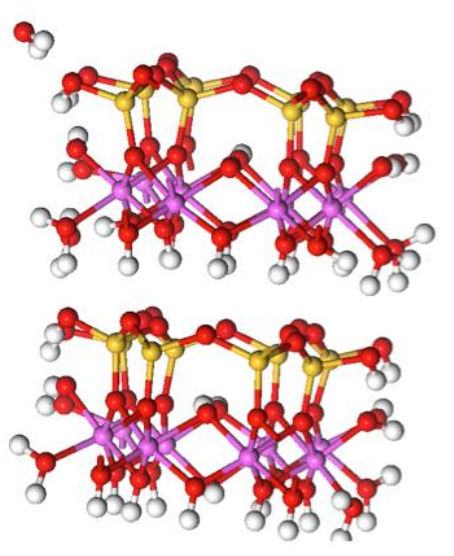

Figure 1. Kaolinite dry edge surfaces: snapshots from DFT-MD. Yellow - Si atoms, pink $\mathrm{Al}$ atoms, red $-\mathrm{O}$ atoms, white $-\mathrm{H}$ atoms. The axes refer to the $\mathrm{AC}$ edge model only. 


\section{METHODS}

\section{DFT}

Periodic DFT calculations used the PBE functional and the D3 dispersion corrections of Grimme et al. ${ }^{50}$ The Gaussian and plane waves (GPW) scheme ${ }^{51}$ was used with a split-valence double-zeta basis set using a single set of polarization functions, ${ }^{52}$ Goedecker-Tetter-Hutter pseudopotentials, ${ }^{53}$ and a plane wave cutoff of 350 Ry for the density grid. Together with the plane wave cutoff, additional GPW settings (relative cutoff, SCF convergence criterion, precision in the calculation of the Kohn-Sham matrix) enabled a small error in the calculated forces $\left(<10^{-4}\right)$. The wavefunction was sampled at the $\Gamma$ point. The $\mathrm{CP} 2 \mathrm{~K}$ software ${ }^{51}$ was used for all DFT calculations.

\section{Force field parameters}

For classical MD simulations, all FF parameters except for the Si-O-H bending term, are presented in Table 2. The nonbonded parameters were taken from the original ClayFF parameterization. ${ }^{29}$ The original harmonic O-H-bond terms for the structural hydroxyl groups were replaced here with a more accurate Morse potential. ${ }^{54} \mathrm{H}_{2} \mathrm{O}$ molecules_-including the $\mathrm{OH}_{2}$ groups attached to the $\mathrm{Al}$ atoms at the edges - are described by the SPC water model ${ }^{55}$ with harmonic $\mathrm{O}-\mathrm{H}$ bond stretching and $\mathrm{H}-\mathrm{O}-\mathrm{H}$ angle bending terms. ${ }^{56}$ The already parameterized Al-O-H term was applied to kaolinite Al-OH groups and not to the $\mathrm{Al}-\mathrm{OH}_{2}$ groups, because of the potential desorption of $\mathrm{OH}_{2}$ groups, observed in our previous work for gibbsite edges. ${ }^{39}$ Ewald summation was used with a cutoff distance of $10 \AA$, the same value being used for the Lennard-Jones terms. 
Table 2. Force Field Parameters

\begin{tabular}{|c|c|c|c|c|}
\hline \multicolumn{5}{|c|}{ Nonbonded $^{[1]}: E_{\text {nonbonded }}=\frac{q_{i} q_{j}}{4 \pi \epsilon_{0} r}+4 \epsilon_{i j}\left[\left(\frac{\sigma_{i j}}{r}\right)^{12}-\left(\frac{\sigma_{i j}}{r}\right)^{6}\right]$} \\
\hline Species & Atom type & $q(\mathrm{e})$ & $\varepsilon\left(\mathrm{kcal} \cdot \mathrm{mol}^{-1}\right)$ & $\sigma(\AA)$ \\
\hline Tetrahedral Si & st & 2.1000 & & \\
\hline Octahedral Al & ao & 1.5750 & $1.3298 \times 10^{-6}$ & 4.2718 \\
\hline Hydroxyl O & oh & -0.9500 & 0.1554 & 3.1655 \\
\hline Hydroxyl H & ho & 0.4250 & 0.000 & 0.0000 \\
\hline Water O & $\mathrm{o}^{*}$ & -0.8200 & 0.1554 & 3.1655 \\
\hline Water H & $\mathrm{h}^{*}$ & 0.4100 & 0.0000 & 0.0000 \\
\hline \multicolumn{5}{|c|}{$E_{\text {Morse }}^{\mathrm{bond}}=D_{0}\left[1-\mathrm{e}^{-\alpha\left(r-r_{0}\right)}\right]^{2}$} \\
\hline Bond & $D_{0}\left(\mathrm{kcal} \cdot \mathrm{mol}^{-1}\right)$ & & $\left(\AA^{-1}\right)$ & $r_{0}(\AA)$ \\
\hline oh-ho ${ }^{[2]}$ & 132.2491 & & .1350 & 0.9450 \\
\hline \multicolumn{5}{|c|}{$E_{\text {harmonic }}^{\text {bond }}=k\left(r-r_{0}\right)^{2}$} \\
\hline Bond & $k\left(\mathrm{kcal} \cdot \mathrm{mol}^{-1} \cdot \AA^{-2}\right)$ & \multicolumn{3}{|c|}{$r_{0}(\AA)$} \\
\hline $\mathrm{o} *-\mathrm{h} *[3]$ & 554.13 & \multicolumn{3}{|c|}{1.0000} \\
\hline \multicolumn{5}{|c|}{$E_{\text {harmonic }}^{\text {angle }}=k\left(\theta-\theta_{0}\right)^{2}$} \\
\hline Angle & $k\left(\mathrm{kcal} \cdot \mathrm{mol}^{-1} \cdot \mathrm{rad}^{-2}\right)$ & \multicolumn{3}{|c|}{$\theta_{0}\left({ }^{\circ}\right)$} \\
\hline $\mathrm{h}^{*}-\mathrm{O}^{*}-\mathrm{h}^{*[3]}$ & 45.770 & \multicolumn{3}{|c|}{109.47} \\
\hline ao-oh-ho ${ }^{[4]}$ & 15 & \multicolumn{3}{|c|}{110} \\
\hline
\end{tabular}

${ }^{[1]}$ Original ClayFF parameters ${ }^{29}$ with $\sigma_{\alpha \beta}=1 / 2\left(\sigma_{\alpha} \sigma_{\beta}\right)$ and $\varepsilon_{\alpha \beta}=\left(\varepsilon_{\alpha} \varepsilon_{\beta}\right)^{1 / 2}$.

${ }^{[2]}$ Set for dioctahedral clays. ${ }^{54}$

${ }^{[3]}$ Ref. 56.

${ }^{[4]}$ Ref. 39. 


\section{Parametrization of the Si-O-H bending term}

The Si-O-H bending term was parameterized in the functional form of

$$
E_{\text {bend }}=k(\theta-\theta 0)^{2},
$$

where $\theta$ is the angle $\angle \mathrm{Si}-\mathrm{O}-\mathrm{H}$ and $k$ is the bending force constant. The algorithm of parametrization was identical to the one used previously for the $\mathrm{Al}-\mathrm{O}-\mathrm{H}$ and $\mathrm{Mg}-\mathrm{O}-\mathrm{H}$ bending terms, ${ }^{39}$ and consisted of finding the values of $k$ and $\theta_{0}$, which minimized the differences between the results of DFT and classical ClayFF-MOH calculations.

First, $\Gamma$-point vibrational modes were calculated using DFT for a given structure after a local geometry optimization. Then, using ClayFF-MOH and the GULP software, ${ }^{57}$ a local geometry optimization was performed starting from the DFT-optimized structure, followed by the calculation of $\Gamma$-point vibrational modes. These calculations were performed for every value of $\theta_{0}$ within the $90-130^{\circ}$ range $\left(\delta \theta=1^{\circ}\right)$, and for every value of $k$ within the $0-40$ $\mathrm{kcal} \cdot \mathrm{mol}^{-1} \cdot \operatorname{rad}^{-2} \mathrm{range}\left(\delta k=1 \mathrm{kcal} \cdot \mathrm{mol}^{-1} \cdot \mathrm{rad}^{-2}\right)$, while all other ClayFF parameters were kept fixed. At the last stage, from the final structures and vibrational normal modes obtained for every pair of parameters $\left(\theta_{0}, k\right)$, absolute differences between DFT- and ClayFF-MOH-derived properties were calculated, in terms of wavenumbers and in terms of $\mathrm{O}-\mathrm{H}$ orientations. The optimization procedure is described in further detail in the Supporting Information of Ref.39. The differences in terms of vibrational frequencies $\langle|\Delta \bar{v}|\rangle$ were also computed, but were not found statistically meaningful due to a high standard error, and thus not conclusive. ${ }^{39}$

It is important to keep in mind, that the model edge surfaces used in the static calculations were hydrated by only one water layer. The surface relaxation of the edge O-H groups and their interaction with liquid water should create additional disorder, thus additional entropic effects. Therefore, the values of the parameters derived from the static energy minimizations are informative but may not necessarily be optimal when all thermodynamic 
effects are included. In the simulations, were have also tested a few other sets of $\left(\theta_{0}, k\right)$ values along with the optimized ones.

\section{Molecular dynamics}

MD simulations were performed at $T=300 \mathrm{~K}$ using a time step of 0.5 fs. DFT Born-Oppenheimer molecular dynamics simulations (DFT-MD) were used for the small structural models. The LAMMPS software,${ }^{58}$ incorporating ClayFF with and without the Al-O$\mathrm{H}$ and Si-O-H bending terms, was used in CMD modeling of larger simulations cells of kaolinite.

Lattice parameters of the large triclinic kaolinite bulk cells were relaxed during CMD simulations in the $N P T$-ensemble at $P=1$ bar using the Nose-Hoover chains thermostat ${ }^{59}$ and the Parrinello-Rahman barostat. ${ }^{60}$ while the small bulk cells were relaxed using DFT cell optimizations. To obtain the equilibrium water density in interfacial simulations, the pores of the small and large edge surface models were filled with 73 and 520 water molecules, respectively. Then the dimension orthogonal to the surface (direction $y$ according to the convention of Fig. 1) was relaxed by performing NPT-ensemble CMD runs on both models for $1 \mathrm{~ns}$, leading up to average equilibrium box lengths along $y$ of $24.3 \AA$ and $46.0 \AA$, respectively. The other two dimensions were derived from the simulations of the bulk crystal cells. After a final equilibration of atomic positions and velocities from $N V T$-simulations for $2 \mathrm{~ns}$ (CMD) and 20 ps (DFT-MD), production runs were performed in the $N V E$ ensemble for 100 ps (CMD) and 40 ps (DFT-MD), collecting atomic positions and velocities every 1 fs. Monitoring the radial distribution functions of the interface atoms over 10 separate windows of $100 \mathrm{ps}$ at equilibrium CMD simulations, no difference was observed, confirming that equilibrium was attained and assuring the convergence of the ensemble averages. By dividing the DFT-MD trajectory into two windows of 20 ps and doing a similar comparison, no significant difference was observed 
within the statistical uncertainty. During the course of the $N V E$-ensemble simulations, the average temperature remained constant within 295-305 K.

\section{RESULTS AND DISCUSSION}

\section{Static calculations}

To estimate the optimal values of the equilibrium angle $\theta_{0}$ and the force constant $k$ for the Si-O-H bending term, the average absolute difference between DFT and ClayFF-MOH OH orientations were compared. Absolute differences for each parameter are shown in Figure 2 for the kaolinite $\mathrm{AC}$-edge model with one water layer on the $\mathrm{AC}_{1}$ and $\mathrm{AC}_{2}$ surfaces. The differences obtained from the $\mathrm{AC}_{1}$ and $\mathrm{AC}_{2}$ surfaces are averaged.

For Si-O-H angle bending, $\left(k, \theta_{0}\right)$ areas leading to the minimal differences-represented by white dots - are quite large, leaving room for compromise with previously reported M-O-H parameters. The parametrized equilibrium angles for $\mathrm{Mg}-\mathrm{O}-\mathrm{H}$ and $\mathrm{Al}-\mathrm{O}-\mathrm{H}$ are $\theta_{0, \mathrm{MgOH}}=\theta_{0, \mathrm{AlOH}}=110^{\circ}$. Figure 2 shows that along the line $\theta_{0}=110^{\circ}$, the Si-O-H $k$ range leading to the minimal $\left\langle\left|\Delta r_{\text {atomic }}\right|\right\rangle$ and $\left\langle\left|\Delta \mathrm{O}-\mathrm{H}_{\text {orientation }}\right|\right\rangle$ values are 8-18 and 7-18 $\mathrm{kcal} \cdot \mathrm{mol}^{-1} \cdot \mathrm{rad}^{-2}$, respectively. Since the value $k_{\mathrm{AlOH}}=15 \mathrm{kcal} \cdot \mathrm{mol}^{-1} \cdot \mathrm{rad}^{-2}$ is within this range, it can $a$ priori be used for the Si-O-H term. In the following, the values $\left[\theta_{0 \mathrm{SiOH}}=110^{\circ} ; k_{\mathrm{SiOH}}=\right.$ $\left.15 \mathrm{kcal} \cdot \mathrm{mol}^{-1} \cdot \mathrm{rad}^{-2}\right]$ will be used for ClayFF-MOH in the CMD simulations. Alternative parameters will be tested if the comparison between DFT-MD and CMD data reveals a possibility for improvement. 
(a)

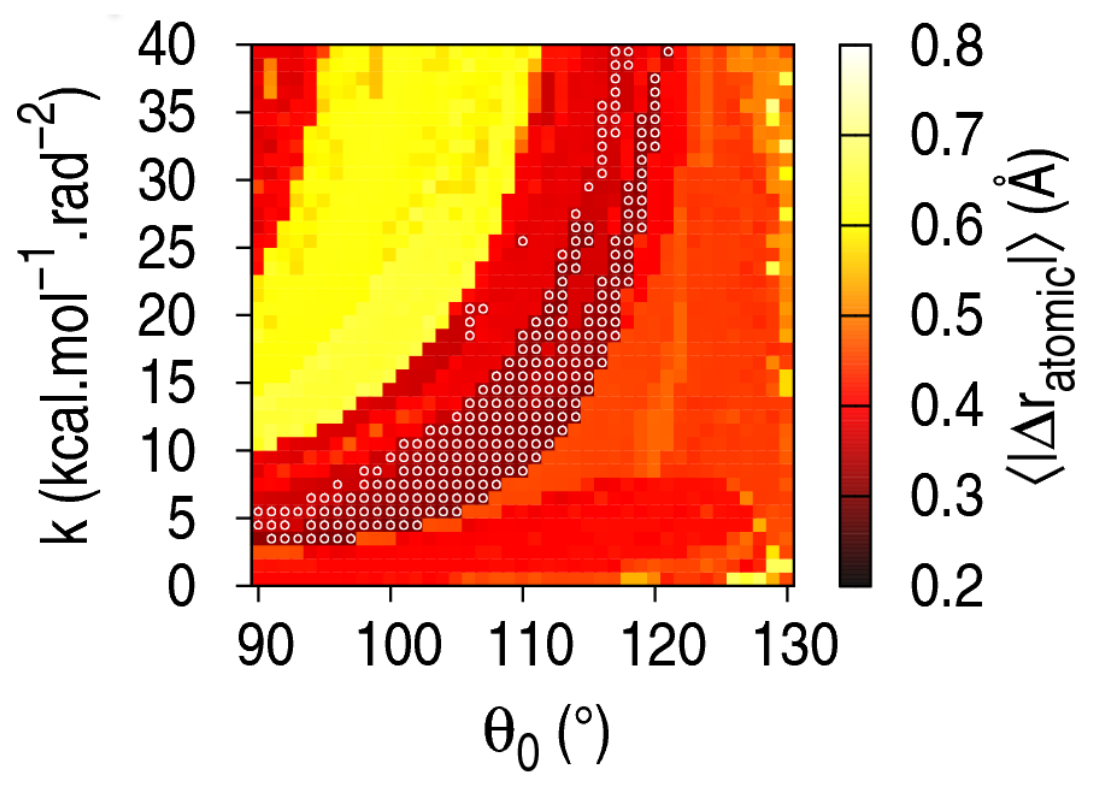

(b)

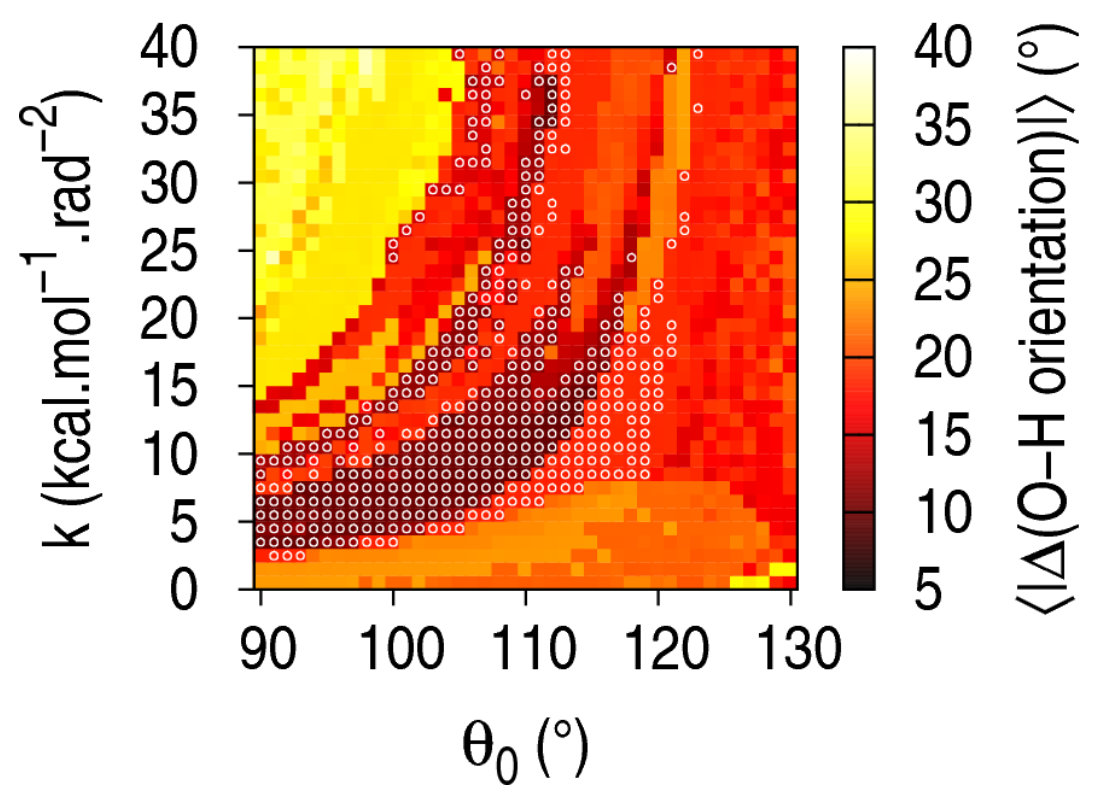

Figure 2. Optimization of the $k$ and $\theta \curvearrowleft 0$ values for the Si-O-H angle bending term from the maps of mean differences between DFT and ClayFF-MOH results in terms of (a) atomic positions and (b) O-H orientation on the kaolinite AC-edge surfaces. The outermost atoms of the two AC-edge surfaces are considered in the mean. The pixels with white circles represent the areas of minimal difference. ${ }^{39}$ 


\section{Proton transfer}

Snapshots from DFT-MD simulations of the hydrated AC surfaces are shown in Figure 3. While no proton exchange was observed between surface hydroxyl groups and interfacial water molecules, multiple proton transfer events occurred at the edge surfaces of kaolinite in DFTMD simulations between silanol groups and neighboring aluminol groups: two Si-O-H groups out of four periodically deprotonated, exchanging the proton with the neighboring Al-O-H group. The proton residence times on either of the sites ranged from 5 to $10 \mathrm{fs}$. A snapshot from the DFT-MD simulation of the $\mathrm{AC}_{2}$ surface is shown in Fig. 3c, illustrating the edge termination after a proton hopping event. To calculate MD-derived structural properties, for each configuration from the DFT-MD trajectory, $\mathrm{OH}$ and $\mathrm{OH}_{2}$ groups were identified based on an O-H distance cutoff of $1.2 \AA$. Such proton transfer events are of course not possible in CMD simulations using ClayFF. The (static) distribution of protonated sites of a surface must be determined as an initial configuration for CMD simulations, depending on factors such as fluid components and desired $\mathrm{pH}$.

\section{Metal-O-H angle and O-H bond orientation of edge hydroxyl groups}

The metal-O-H angle $(\angle \mathrm{MOH})$ distribution is a convenient first indicator of the bending term performance, both in terms of the angle of maximum probability and of the amplitude of the metal-O-H bending (Fig. 4). A more useful descriptor of surface hydroxyls is the absolute orientation of the $\mathrm{O}-\mathrm{H}$ bond, shown as distributions of the $\mathrm{OH}$ vector in the $y z$ plane are shown in Fig. 5. Here $z$ the direction of the stacking of the tetrahedral and octahedral sheets and $x$ the direction orthogonal to the surface (Fig. 3). 


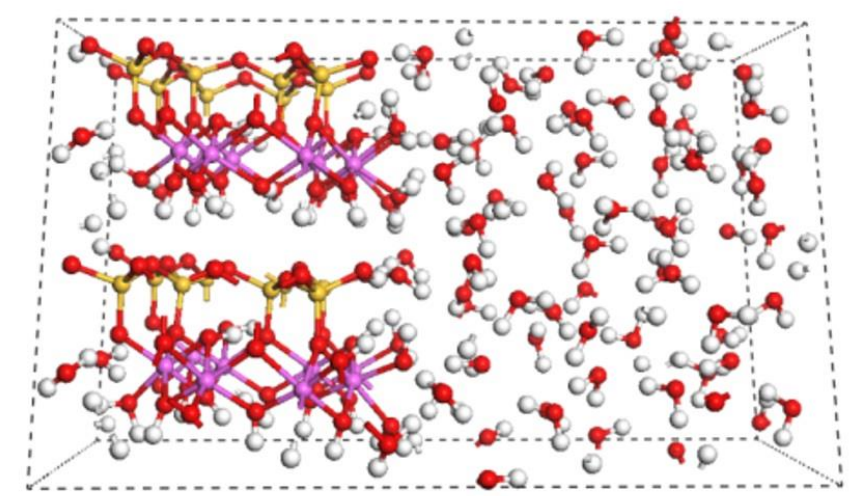

(a)

(b)
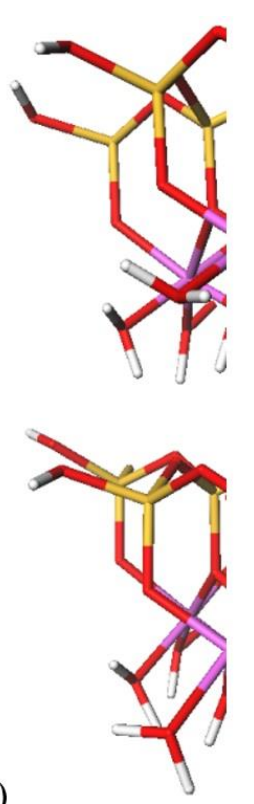
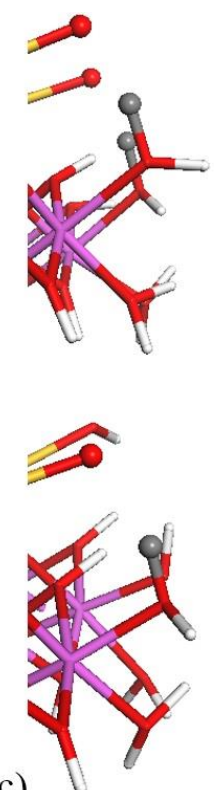

(c)

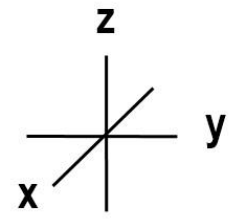

Figure 3. Snapshots from DFT-MD simulations of the (a) hydrated AC surface, (b) $A_{1}$ surface, and (c) $\mathrm{AC}_{2}$ surface. In the initial configuration (a) the surface consists of $4 \mathrm{SiOH}$ sites and $4 \mathrm{Al}(\mathrm{OH})\left(\mathrm{OH}_{2}\right)$ sites. In this snapshot the surface is terminated by $1 \mathrm{SiOH}, 1 \mathrm{Al}(\mathrm{OH})\left(\mathrm{OH}_{2}\right), 3 \mathrm{SiO}-$ and $3 \mathrm{Al}\left(\mathrm{OH}_{2}\right)\left(\mathrm{OH}_{2}\right)$ sites; the atoms represented by gray balls illustrate the proton transfers from the $\mathrm{SiOH}$ groups to the $\mathrm{AlOH}$ groups. Axes are shown for comparison with Fig. 5. 
(a) $\mathrm{AC}_{1}$ surface

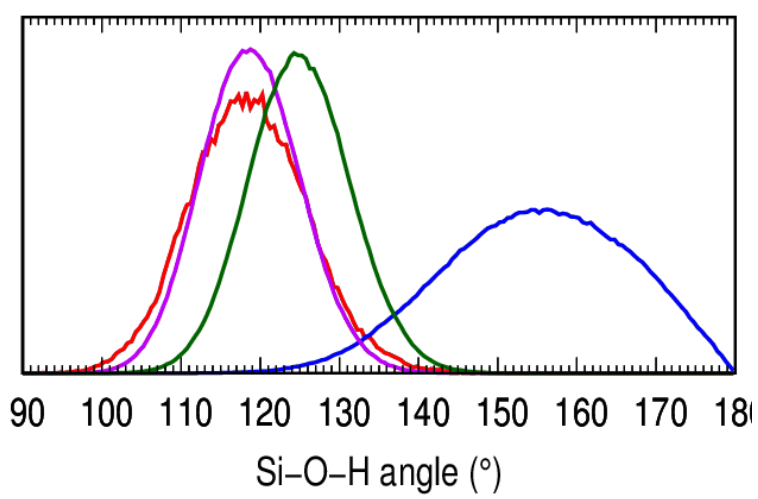

(b) $\mathrm{AC}_{2}$ surface

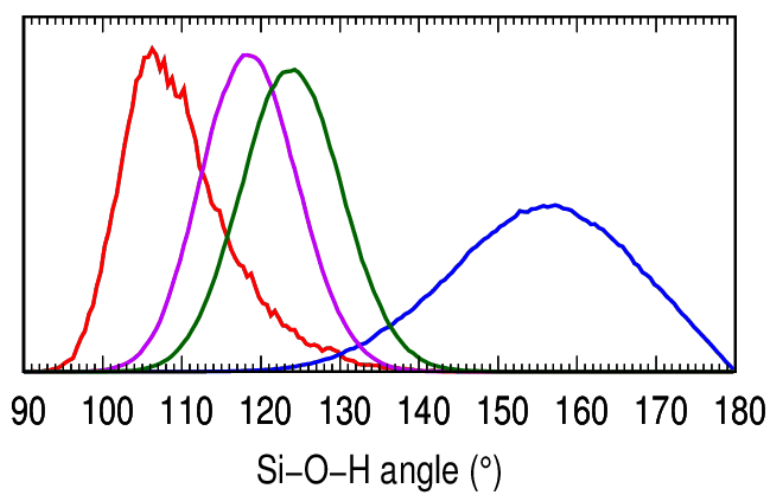

(c) $\mathrm{AC}_{2}$ surface

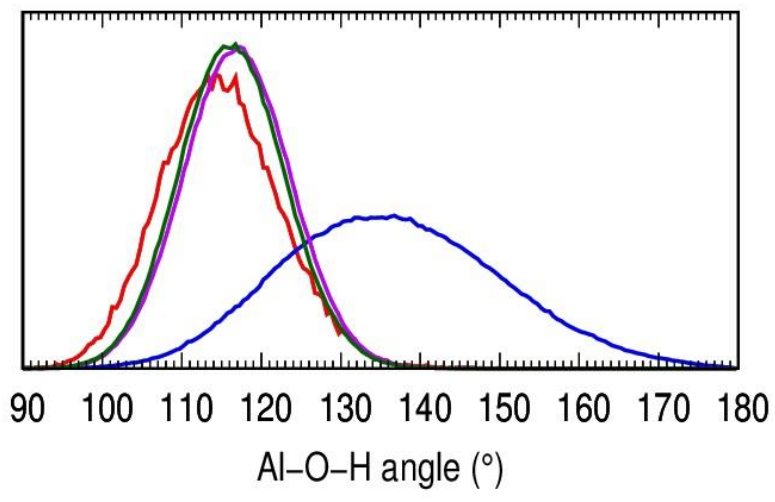

Figure 4. $\angle \mathrm{Si}-\mathrm{O}-\mathrm{H}$ and $\angle \mathrm{Al}-\mathrm{O}-\mathrm{H}$ angle distributions for the $\mathrm{OH}$ groups on the kaolinite $\mathrm{AC}_{1}$ (a) and $\mathrm{AC}_{2}$ (b),(c) edge surfaces. On the $\mathrm{AC}_{1}$ surface, all $\mathrm{Al}$ atoms are coordinated to $\mathrm{OH}_{2}$ groups only. ${ }^{[1]} \theta_{0, \mathrm{AlOH}}=110^{\circ}$ and $k_{\mathrm{SiOH}}=k_{\mathrm{AlOH}}=15 \mathrm{kcal} \cdot \mathrm{mol}^{-1} \cdot \mathrm{rad}^{-2}$.

\section{$\underline{\text { Silanol groups }}$}

The Si-O-H angles corresponding to the maxima of the distributions of the $\mathrm{AC}_{1}$ and the $\mathrm{AC}_{2}$ edge surfaces obtained by DFT-MD are $\angle \mathrm{SiOH}^{\max }=119^{\circ}$ and $\angle \mathrm{SiOH}^{\mathrm{max}}=107^{\circ}$ respectively, with their full width at half-maximum (FWHM), respectively, at $18.1^{\circ}$ and $13.5^{\circ}$. The distribution for the $\mathrm{AC}_{2}$ surface is noticeably asymmetric exhibiting a shoulder due to a secondary distribution centered approximately around $110^{\circ}$.

As seen in Fig. 5a and illustrated in Fig.3b, the Si-O-H groups on the $\mathrm{AC}_{1}$ surface are subject to reorientations during the simulation with a seemingly continuous orientation pattern in the $y z$ plane, while the most probable orientation is at $y \sim-0.7 \AA, z \sim-0.4 \AA$. However, the 
Si-O-H groups on the $\mathrm{AC}_{2}$ surface adopt two distinct and more restrained orientations, the most probable of which being at $y=+0.7 \AA, z=-0.8 \AA$.

(a) $\mathrm{AC}_{1}$

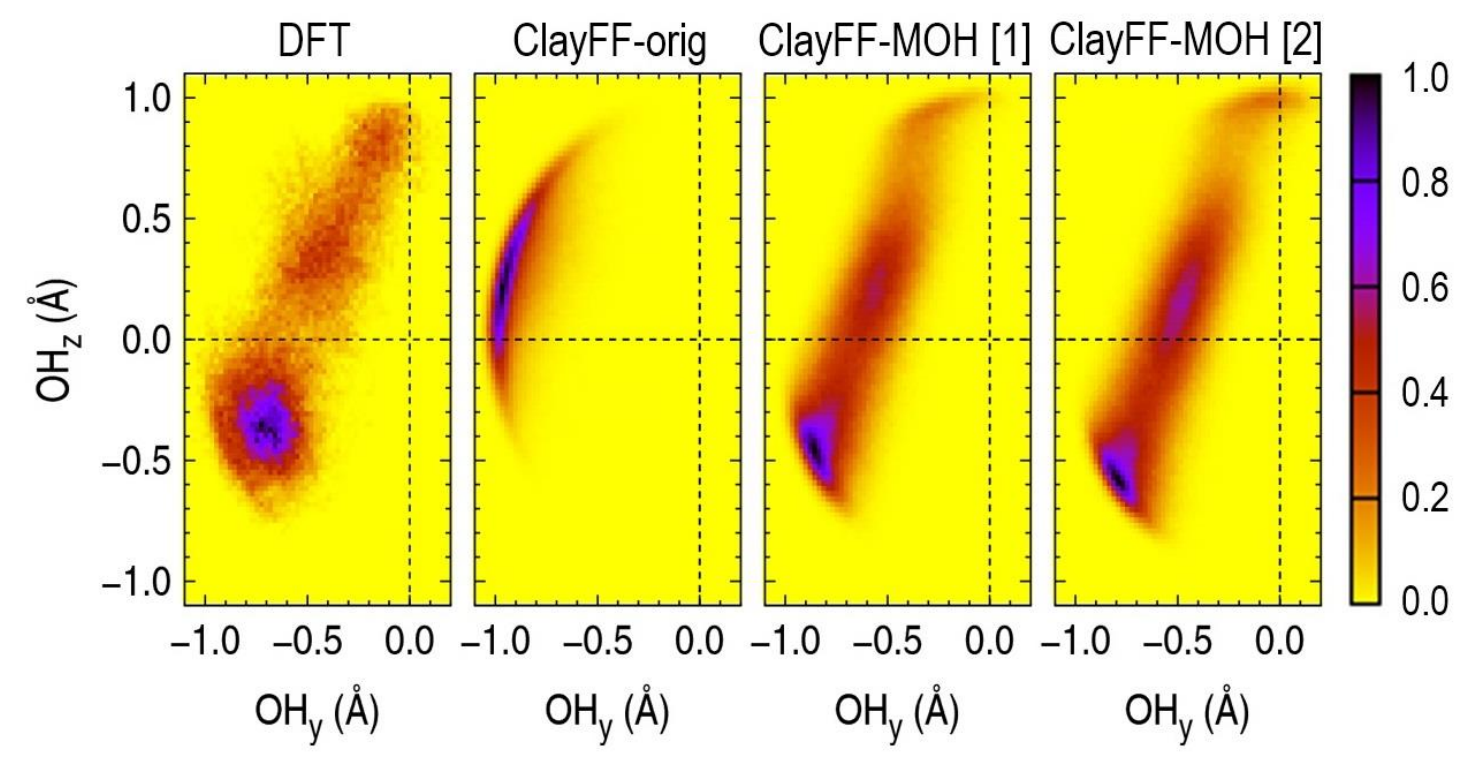

(b) $\mathrm{AC}_{2}$

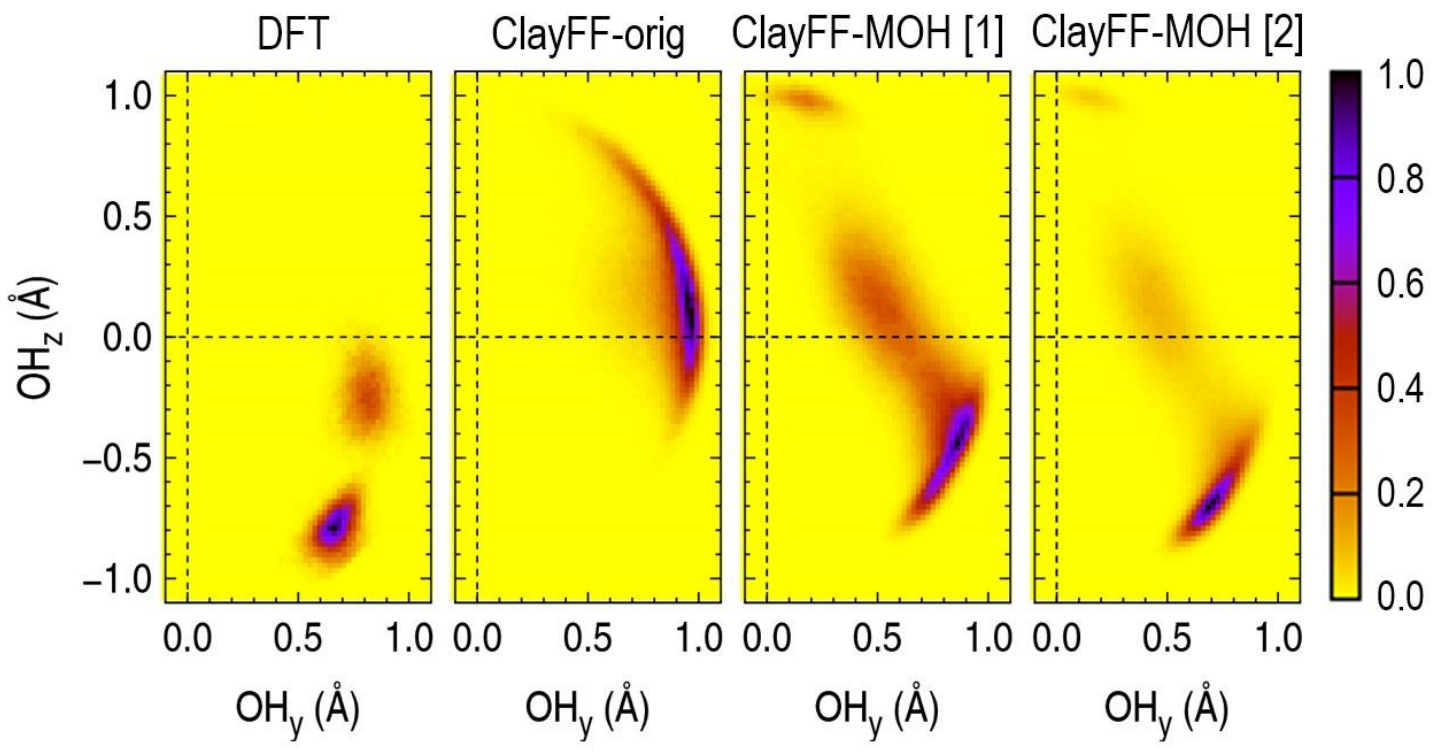

Figure 5. Orientation of the kaolinite Si-O-H belonging to the $\mathrm{AC}_{1}$ and $\mathrm{AC}_{2}$ edge surfaces. The distribution of the $\mathrm{O}-\mathrm{H}$ bond vectors projected on the $y z$ crystallographic plane from DFT, ClayFF-orig and ClayFF-MOH MD simulations. The color range from the lowest to the highest intensity is yellow, red, and black. [1] $\theta_{0, \mathrm{SiOH}}=110^{\circ}$ and $k_{\mathrm{SiOH}}=k_{\mathrm{AlOH}}=15 \mathrm{kcal} \cdot \mathrm{mol}^{-1} \cdot \mathrm{rad}^{-2} \cdot[2] \theta_{0, \mathrm{SiOH}}=100^{\circ}$ and $k_{\mathrm{SiOH}}=k_{\mathrm{AlOH}}=$ $15 \mathrm{kcal} \cdot \mathrm{mol}^{-1} \cdot \mathrm{rad}^{-2}$. 
The distributions obtained with CMD without M-O-H terms (ClayFF-orig) have a very small overlap with the DFT-MD distribution, due to the much more obtuse $\angle \mathrm{SiOH}^{\text {max }}$ angle at $156^{\circ}$. The distributions are also broader with their FWHM values almost doubled in extent. Using ClayFF-MOH with the angle bending parameters deduced from the static calculations $\left(\theta_{0, \mathrm{SiOH}}=110^{\circ}\right.$ and $\left.k_{\mathrm{SiOH}}=15 \mathrm{kcal} \cdot \mathrm{mol}^{-1} \cdot \mathrm{rad}^{-2}\right)$ clearly narrows the distribution and brings it much closer to the DFT-MD results, with FWHM values of $16^{\circ}$ and $15^{\circ}$, respectively, for the $\mathrm{AC}_{1}$ and $\mathrm{AC}_{2}$ surfaces. However, the distributions are centered around $\angle \mathrm{SiOH}^{\mathrm{max}}=125^{\circ}$ for the two surfaces. While the $\angle \mathrm{SiOH}^{\mathrm{max}}$ difference of the results for the $\mathrm{AC}_{1}$ surface is around $6^{\circ}$, the difference of $18^{\circ}$ for the $\mathrm{AC}_{2}$ surface is less acceptable. Therefore, we performed CMD simulations with a lower value of the Si-O-H equilibrium angle $\theta_{0}=100^{\circ}$ for ClayFF-MOH, to evaluate its effect on the $\angle \mathrm{SiOH}$ distribution. As a result, the distributions are shifted to lower angles of $118^{\circ}$ and $117^{\circ}$, i.e., significantly closer to the DFT-MD values for both the $\mathrm{AC}_{1}$ and the $\mathrm{AC}_{2}$ surfaces (Fig.4a,b).

These improvements in terms of angular distributions translate into more realistic $\mathrm{O}-\mathrm{H}$ orientations as seen in Fig. 5. On the $\mathrm{AC}_{1}$ surface, the region of higher probability $\mathrm{O}-\mathrm{H}$ orientation predicted by ClayFF-MOH agrees well with DFT-MD, with the most probable orientation being in the lower left quadrant in the $y z$ plane $(y \sim-0.8 \AA$ to $-0.9 \AA, z \sim-0.5 \AA$ to $0.6 \AA)$ and extending along a segment until the $+z$ orientation $(y \sim 0, z \sim 1.0 \AA)$. On the $\mathrm{AC}_{2}$ surface, while the agreement between ClayFF-MOH and DFT-MD results is less pronounced, the region of the most probable $\mathrm{Si}-\mathrm{O}-\mathrm{H}$ orientations in the $+y,-z$ quadrant is significantly improved compared to performance of ClayFF-orig.

\section{$\underline{\text { Aluminol groups }}$}

Similar to the gibbsite (100) edge surface in our previous work, ${ }^{39}$ Fig. $4 \mathrm{c}$ shows that the $\mathrm{Al}-\mathrm{O}-\mathrm{H}$ term dramatically improves the corresponding angle distribution on the $\mathrm{AC}_{2}$ surface. 
The agreement between DFT-MD and ClayFF-MOH is clear, with $\angle \mathrm{AlOH}^{\text {max }}$ values of $114^{\circ}$ and $117^{\circ}$, respectively. The FWHM values are $18^{\circ}$ and $15^{\circ}$, while for ClayFF-orig the $\angle \mathrm{AlOH}^{\text {max }}$ is $135^{\circ}$ and the FWHM is $34^{\circ}$ (Fig. 4c). Understandably, the Al-O-H angle distribution is not significantly affected by the $\theta_{0}$, SiOH value.

\section{$\mathrm{Al}-\mathrm{OH}$ and $\mathrm{Al}-\mathrm{OH}_{2}$ coordination on the $\mathrm{AC}_{2}$ surface}

No migration of $\mathrm{OH}$ groups was observed during the DFT-MD or the CMD simulations from any kaolinite edge surface. Similarly, on the $\mathrm{AC}_{1}$ surface, no $\mathrm{H}_{2} \mathrm{O}$ desorption was observed with either DFT-MD or CMD set of simulations. DFT-MD does not predict any $\mathrm{H}_{2} \mathrm{O}$ or $\mathrm{OH}$ desorption with a total $\mathrm{Al}-\mathrm{O}_{\text {surface }}$ coordination number equal to 2.00 (i.e., a total $\mathrm{Al}-\mathrm{O}$ coordination of 6.00). Proton transfer events observed during DFT-MD simulations result in a Al- $\mathrm{OH}_{2}$ coordination number of 1.41 compared to 1.00 in the pre-equilibrated structure (Fig. 6).

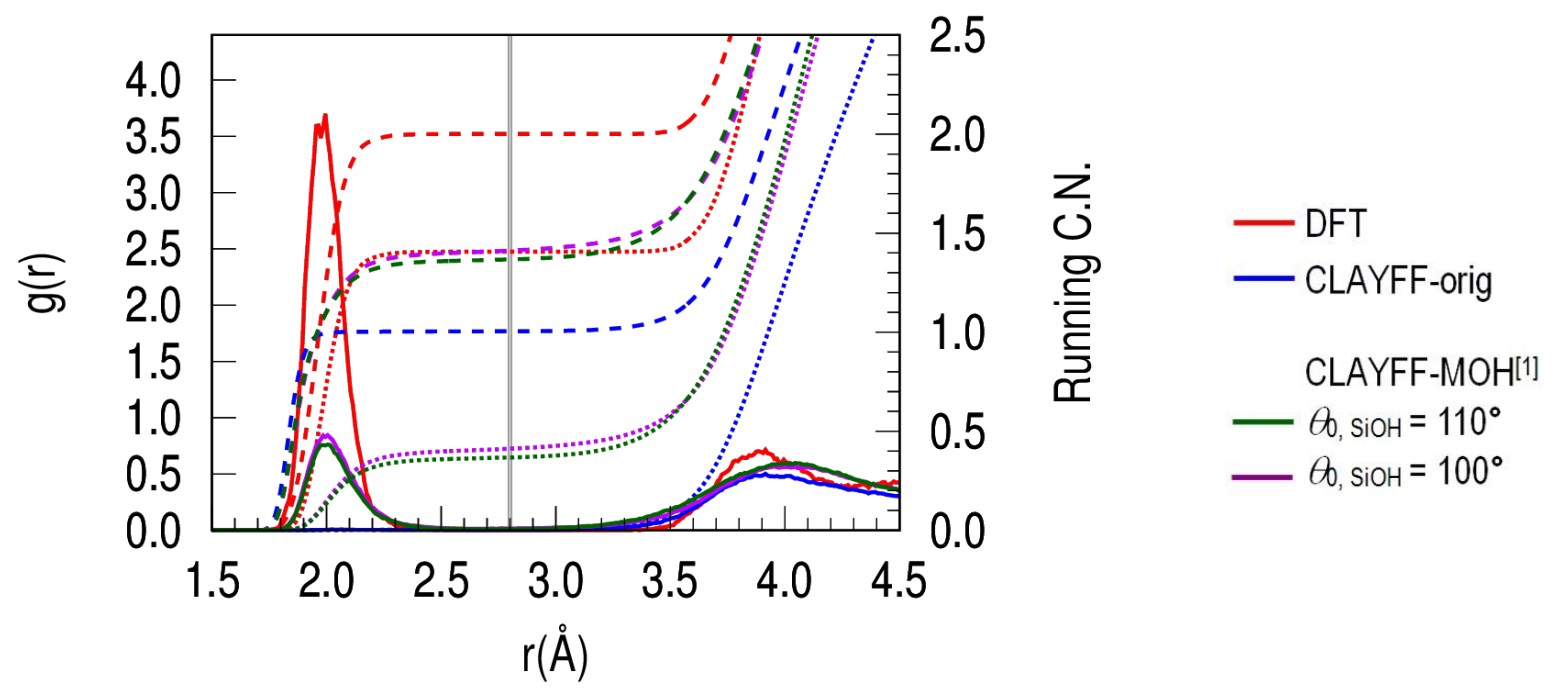

Figure 6. Radial distribution functions (solid lines) and running coordination numbers for $\mathrm{Al}-\mathrm{O}_{\mathrm{H} 2 \mathrm{O}}$ (dotted lines) and $\mathrm{Al}-\mathrm{O}_{(\mathrm{H} 2 \mathrm{O}+\mathrm{OH})}$ (dashed lines) at the kaolinite edge surfaces. The vertical gray line indicates the cutoff distance used to determine the first neighbor coordination numbers mentioned in the text. ${ }^{[1]} \theta_{0, \mathrm{AlOH}}=110^{\circ}$ and $k_{\mathrm{SiOH}}=k_{\mathrm{AlOH}}=15 \mathrm{kcal} \cdot \mathrm{mol}^{-1} \cdot \mathrm{rad}^{-2}$. 
Some of the initially adsorbed $\mathrm{H}_{2} \mathrm{O}$ molecules were later desorbed during the CMD simulations, as illustrated by the $\mathrm{Al}-\mathrm{O}_{\mathrm{H} 2 \mathrm{O}}$ coordination numbers of $0.00,0.37$ and 0.41 obtained, respectively, by ClayFF-orig, ClayFF-MOH with $\theta_{0, \mathrm{SiOH}}=100^{\circ}$, and ClayFF-MOH with $\theta_{0, \mathrm{SiOH}}=110^{\circ}$ (Fig. 6). Contrary to the ClayFF-orig results, the ClayFF-MOH results are in agreement with previous DFT calculations predicting that 5- and 6-coordinated $\mathrm{Al}$ atoms should be present on the surface. ${ }^{44}$ These results indicate the insufficient timescale of the unconstrained DFT-MD simulations to correctly model this process: during equilibration several hundred ps were necessary to reach a stable configuration in the repartitioning of adsorbed and desorbed $\mathrm{H}_{2} \mathrm{O}$ molecules.

Additionally, if the angle bending term is turned off for bulk Al-OH groups but preserved for surface groups, then all $\mathrm{H}_{2} \mathrm{O}$ molecules are desorbed. Therefore, the interaction between kaolinite basal layers, affected by the angle bending term when it is applied to bulk Al-OH groups, influences surface properties. One can assume that strengthening the layer-to-layer Hbonding due to the M-O-H term also facilitates strengthening of the hydrogen bonding network on the edge surface.

\section{Hydrogen bonding at the hydrated kaolinite edge surfaces}

One of the geometric criteria used to assess if two species are hydrogen-bonded is the $\mathrm{H}_{\text {donor }} \cdots \mathrm{O}_{\text {acceptor }}$ distance, whose cutoff can be obtained from the position of the first minimum of the corresponding donor-acceptor radial distribution functions. In the current work, depending on the hydrogen bond (HB) donor-acceptor pair and the modeling method, this minimum—usually clearly visible — varies between 2.3 - 2.6 A (See Figure S1 of Supporting Information). Therefore, for all $\mathrm{HB}$ pairs we consider a uniform $\mathrm{H}$... $\mathrm{O}_{\text {acceptor }}$ cutoff distance of $R_{\mathrm{HB}}=2.45 \AA$, which is also the generally accepted value for a water-water H-bonds. ${ }^{61}$ Additionally, for all the reported $\mathrm{HBs}$ the average $\mathrm{O}_{\text {donor }}-\mathrm{H}_{\ldots} . \mathrm{O}_{\text {acceptor }}$ angle was greater than 
$130^{\circ}$, which is also consistent with the angular range of HBs in bulk liquid water (see, e.g., Ref. 62).

Hydrogen bonding at the edge surfaces of kaolinite has previously been studied by means of DFT-MD simulations. ${ }^{44}$ Here, HBs significantly affected by the M-O-H term are those involving $\mathrm{Al}-\mathrm{OH}$ and $\mathrm{Si}-\mathrm{OH}$ groups, therefore $\mathrm{H}$-bonding between $\mathrm{H}_{2} \mathrm{O}$ molecules and $\mathrm{Al}-\mathrm{OH}_{2}$ groups on both edge surfaces or apical $\mathrm{O}(\mathrm{Al}-\mathrm{O}-\mathrm{Si})$ on the $\mathrm{AC}_{1}$ surface will not be discussed.

The new angle bending parameterization does not significantly affect the H-bond lengths, which are already satisfactorily close to the DFT results with the ClayFF-orig model (i.e., within $0.10 \AA$ for most HBs). The difference between DFT and ClayFF-orig results in terms of $\mathrm{H}$ bonding essentially lies in the number of $\mathrm{H}$-bonds formed (NHB), which is calculated here as the running coordination number $(\mathrm{RCN})$ of the donor-acceptor pairs from the corresponding radial distribution functions and using the $R_{\mathrm{HB}}$ cutoff distance. The NHB values are reported in Table 3.

\section{$\underline{\text { AC }}$ 1 surface}

DFT-MD simulations predict that on the $\mathrm{AC}_{1}$ surface $\mathrm{Si}-\mathrm{OH}$ groups donate and accept $1.0 \mathrm{HB}$ from bulk $\mathrm{H}_{2} \mathrm{O}$ molecules, in agreement with the previous DFT-MD study. ${ }^{44} \mathrm{CMD}$ simulations with the three FF versions underestimate the NHB. ClayFF-MOH with $\theta_{0, \mathrm{SiOH}}=110^{\circ}$ gives the closest NHB value to DFT-MD one: 0.81 and 0.97 , respectively (Table 3 ).

The $\mathrm{HBs}$ donated by $\mathrm{Al}-\mathrm{OH}_{2}$ groups to $\mathrm{Si}-\mathrm{OH}$ groups occur between different layers at the kaolinite edge surface, therefore the NHB depends on the alignment between layers. When the layers are perfectly aligned (e.g., 2-layer model used in DFT calculations, Fig. 3a), these HBs are not favored $(\mathrm{NHB}=0.12)$. However, if there is a slight shift between the layers (as it is observed in the CMD simulations for a 4-layer model), and the most probable orientation of Si$\mathrm{O}-\mathrm{H}$ groups is shifted slightly downwards with the ClayFF-MOH parametrization (Fig. 5a), then $\mathrm{Al}-\mathrm{OH}_{2}$ groups can donate $\mathrm{HBs}$ to $\mathrm{Si}-\mathrm{OH}$ (Table $\left.3, \mathrm{NHB}=0.67-0.70\right)$. Of course, the real 
alignment heterogeneity of the kaolinite layers in laboratory samples cannot be correctly captured by a simple 2-layer structural model used for DFT-MD simulations.

Table 3. Average number of $\mathrm{HBs}$ (NHB) for different donor-acceptor HB pairs at the kaolinite $\mathrm{AC}_{1}$ and $\mathrm{AC}_{2}$ edge surfaces.

\begin{tabular}{|c|c|c|c|c|c|c|}
\hline Donor & Acceptor & $\begin{array}{c}\text { DFT }^{[1]} \\
\text { current work }\end{array}$ & DFT $^{[2]}$ & ClayFF-orig & ClayFF-MOH $^{[3]}$ & ClayFF-MOH $^{[4]}$ \\
\hline \multicolumn{7}{|c|}{ Bulk } \\
\hline $\mathrm{Al}_{2} \mathrm{OH}$ & $\mathrm{Si}_{\mathrm{Si}}$ & & & & & \\
\hline \multicolumn{7}{|c|}{$\mathbf{A C}_{1}$} \\
\hline${ }_{\mathrm{Al}} \mathrm{OH}_{2}$ & $\mathrm{si}_{\mathrm{i}} \mathrm{OH}$ & 0.12 & & $\underline{0.07^{[5]}}$ & 0.70 & 0.67 \\
\hline water & $\mathrm{si} \mathrm{OH}$ & 1.05 & $\sim 1.0$ & 0.65 & $\underline{0.81}$ & 0.69 \\
\hline $\mathrm{Si}_{\mathrm{Si}} \mathrm{OH}$ & water & 0.99 & $\sim 1.0$ & 0.86 & $\underline{0.97}$ & 0.93 \\
\hline All & ${ }_{\mathrm{Si}} \mathrm{OH}$ & 1.17 & & 0.72 & 1.52 & $\underline{1.36}$ \\
\hline \multicolumn{7}{|c|}{$\mathrm{AC}_{2}$} \\
\hline${ }_{\mathrm{Al}} \mathrm{OH}_{2}$ & $\mathrm{si}_{\mathrm{i}} \mathrm{OH}$ & 0.62 & & 0.00 & 0.19 & $\underline{0.29}$ \\
\hline water & $\mathrm{si} \mathrm{OH}$ & 0.37 & & $\underline{0.19}$ & 0.61 & 0.75 \\
\hline $\mathrm{Si} \mathrm{OH}$ & water & 0.33 & $\begin{array}{l}0.0(5-c .) \\
1.0(6-c .)\end{array}$ & 0.76 & 0.56 & $\underline{0.38}$ \\
\hline${ }_{\mathrm{Si}} \mathrm{OH}$ & ${ }_{\mathrm{Al}} \mathrm{OH}$ & 0.61 & & 0.08 & 0.27 & $\underline{0.49}$ \\
\hline water & ${ }_{\mathrm{Al}} \mathrm{OH}$ & 1.33 & $\begin{array}{l}1.0(6-c .) \\
1.8(5-c .)\end{array}$ & 1.60 & 1.64 & $\underline{1.42}$ \\
\hline${ }_{\mathrm{Al}} \mathrm{OH}$ & water & 0.79 & $\begin{array}{l}1.0(6-c .) \\
0.8(5-c .)\end{array}$ & $\underline{0.79}$ & $\underline{0.61}$ & $\underline{0.73}$ \\
\hline All & $\mathrm{si} \mathrm{OH}$ & 0.99 & & 0.21 & $\underline{1.00}$ & $\underline{1.10}$ \\
\hline $\mathrm{Si}_{\mathrm{i}} \mathrm{OH}$ & All & 0.94 & & 0.84 & 0.83 & 0.86 \\
\hline All & ${ }_{\mathrm{Al}} \mathrm{OH}$ & 1.95 & & 1.67 & $\underline{1.91}$ & $\underline{1.90}$ \\
\hline${ }_{\mathrm{Al}} \mathrm{OH}$ & All & 0.79 & & $\underline{0.81}$ & $\underline{0.81}$ & $\underline{0.79}$ \\
\hline
\end{tabular}

${ }^{[1]} \mathrm{HB}$ types with NHB $<0.10$ by DFT-MD are not shown here.

${ }^{[2]}$ Estimated from the results of Liu et al. ${ }^{44}$; values for both 5-coordinate and 6-coordinate edge $\mathrm{Al}$ atoms are shown.

${ }^{[3]} \theta_{0}, \mathrm{SiOH}=110^{\circ}, \theta_{0}, \mathrm{AlOH}=110^{\circ}$ and $k_{\mathrm{SiOH}}=k_{\mathrm{AlOH}}=15 \mathrm{kcal} \cdot \mathrm{mol}^{-1} \cdot \mathrm{rad}^{-2}$.

${ }^{[4]} \theta_{0}, \mathrm{SiOH}=100^{\circ}, \theta_{0}, \mathrm{AlOH}=110^{\circ}$ and $k_{\mathrm{SiOH}}=k_{\mathrm{AlOH}}=15 \mathrm{kcal} \cdot \mathrm{mol}^{-1} \cdot \mathrm{rad}^{-2}$.

${ }^{[5]}$ For ClayFF-MOH results the NHBs within 0.20 units of the DFT-MD values are underlined. 


\section{$\underline{A C_{2}} \underline{\text { surface }}$}

The H-bonding topologies of the $\mathrm{AC}_{2}$ surface differ between DFT-MD and CMD in two ways: (i) $\mathrm{H}_{2} \mathrm{O}$ desorption is observed only by CMD and (ii) proton transfer between $\mathrm{Al}$ and $\mathrm{Si}$ sites is obviously observed only by DFT-MD. HBs will be necessarily affected by the protonation and coordination of the $\mathrm{Al}$ sites and difference in topologies, in addition to the differences inherent in the interaction models.

DFT-MD predicts that $\mathrm{Si}-\mathrm{OH}$ groups donate $0.61 \mathrm{HBs}$ to the neighboring Al-OH groups and $0.33 \mathrm{HBs}$ to surface $\mathrm{H}_{2} \mathrm{O}$ molecules. As previously shown by Liu et al. ${ }^{44}$, when the $\mathrm{Al}$ sites are 5-coordinated, the distance between $\mathrm{Al}-\mathrm{OH}$ groups and $\mathrm{Si}-\mathrm{O}-\mathrm{H}$ groups is too large for the two groups to form a stable H-bond. Since with ClayFF-orig the Al sites are all 5-coordinated, Si-OH groups do not donate $\mathrm{HBs}$ to $\mathrm{Al}-\mathrm{OH}$ groups $(\mathrm{NHB}=0.08)$ in favor of water molecules $(\mathrm{NHB}=0.76)$. The more realistic $\mathrm{AC}_{2}$ surfaces obtained from ClayFF-MOH feature both 5and 6-coordinations, and this results in $\mathrm{Si}-\mathrm{O}-\mathrm{H}$ groups donating 0.27 and 0.49 to $\mathrm{Al}-\mathrm{OH}$ groups for $\theta_{0, \mathrm{SiOH}}=110^{\circ}$ and $\theta_{0, \mathrm{SiOH}}=100^{\circ}$ parametrizations, respectively.

According to DFT-MD, water molecules interact with the $\mathrm{AC}_{2}$ surface by $\mathrm{H}$-bonding primarily with $\mathrm{Al}-\mathrm{OH}$ groups rather than $\mathrm{Si}-\mathrm{OH}$ groups, and this is particularly true for the $\mathrm{H}$ bonds accepted by $\mathrm{M}-\mathrm{OH}$ groups: $1.33 \mathrm{HBs}$ are accepted by $\mathrm{Al}-\mathrm{OH}$ groups from water molecules compared with $0.37 \mathrm{HBs}$ accepted by $\mathrm{Si}-\mathrm{OH}$ groups. The latter NHB is not well reproduced by ClayFF-MOH (0.61-0.75), but here the classical force field model is not necessarily less realistic than the DFT result, since this higher value is correlated with the situation where one of the HBs accepted by the $\mathrm{Si}-\mathrm{OH}$ group is donated by an $\mathrm{Al}-\mathrm{OH}_{2}$ group from the neighboring layer. Indeed, similar to the $\mathrm{AC}_{1}$ surface, $\mathrm{H}$-bonding from $\mathrm{Al}-\mathrm{OH}_{2}$ groups to $\mathrm{Si}-\mathrm{OH}$ groups depends on the registry shift of the kaolinite layers with respect to each other, which is probably incorrectly captured using a relatively small DFT model. 
Overall, in terms of hydrogen bonding, $\theta_{0, \mathrm{SiOH}}=100^{\circ}$ performs better than $\theta_{0, \mathrm{SiOH}}=110^{\circ}$ on the $\mathrm{AC}_{2}$ surface, in agreement with the better performance in terms of angle distributions (Figure 4b). The two parameterizations give very similar results for the $\mathrm{AC}_{1}$ surface.

Regarding H-bonds accepted by Al-OH groups from water molecules, ClayFF-MOH with $\theta_{0, \mathrm{AlOH}}=110^{\circ}$ clearly improves on ClayFF-orig, with $\mathrm{NHB}=1.42$.

\section{Effect of the M-O-H bending term on the bulk crystal lattice parameters}

Bulk crystal properties are particularly important not only by themselves, but when they are correlated with surface properties in the context of simulating realistic mineral platelets, and specifically non-swelling mineral particles. Obtaining $\mathrm{M}-\mathrm{O}-\mathrm{H}$ bending parameters which result in accurate bulk properties, e.g. crystal lattice parameters, is important even if less central than surface properties in the present context. An illustration of the influence of the $\theta_{0}$ parameter on the lattice parameters of four representative $\mathrm{AlOH}$-containing layered minerals is given in Table 4. The difference in lattice parameters derived from CMD values with respect to experimental data is based on the lattice vectors $\left(\mathbf{u}_{1}, \mathbf{u}_{2}, \mathbf{u}_{3}\right)$ :

$$
\frac{\sum_{i=1}^{3}\left\|\mathbf{u}_{\mathbf{i}}-\mathbf{u}_{\mathbf{i} \text { ref. }}\right\|}{\sum_{\mathrm{i}=1}^{3}\left\|\mathbf{u}_{\mathbf{i} \text { ref. }}\right\|}, \text { with }\left\|\mathbf{u}_{\mathbf{1}}\right\|=\mathrm{a},\left\|\mathbf{u}_{\mathbf{2}}\right\|=\mathrm{b},\left\|\mathbf{u}_{\mathbf{3}}\right\|=\mathrm{c}
$$

The data in Table 4 indicate that the bulk lattice parameters show an exceptional dependence on $\theta_{0, \mathrm{AlOH}}$. Assuming, quite arbitrarily, that an error of $2.5 \%$ or less is acceptable, Table 4 shows that a single $\theta_{0, \mathrm{AlOH}}$ value which satisfies this condition for all four minerals cannot be found. However, it is satisfied with $\theta_{0, \mathrm{AlOH}}=115-116^{\circ}$ for gibbsite, boehmite and pyrophyllite and with $\theta_{0, \mathrm{AlOH}}=120^{\circ}$ for gibbsite, boehmite and kaolinite. Since $\theta_{0, \mathrm{AlOH}}=110^{\circ}$ is the most appropriate value for surface properties, selecting the same value for the bulk $\mathrm{AlOH}$ groups leads to a reduced error with respect to the lattice parameters obtained from ClayFF- 
orig for gibbsite, boehmite and pyrophyllite, thus depending on the desired accuracy it may be unnecessary to differentiate bulk and surface $\mathrm{Al}-\mathrm{OH}$ groups in terms of the FF parameters. However, $\theta_{0, \mathrm{AlOH}}=116^{\circ}$ is the most optimal value for bulk properties, and we recommend this value when separate $\theta_{0, \mathrm{AlOH}}$ parameters are desired for bulk and surface $\mathrm{Al}-\mathrm{OH}$ groups. Further improvement in the accuracy of the FF could involve distinct parameters for bulk and surface, as it was shown for the point charges (e.g., Refs. 37, 63).

Table 4. Errors (\%, eq.(3)) of bulk crystal lattice parameters calculated by CMD for four $\mathrm{AlOH}$-containing minerals as a function of the $\theta_{0, \mathrm{AlOH}}$ value with a constant $k_{\mathrm{AlOH}}=15 \mathrm{kcal} \cdot \mathrm{mol}^{-1} \cdot \mathrm{rad}^{-2}$.

\begin{tabular}{|c|c|c|c|c|c|}
\hline & $\theta_{0}$ & $\begin{array}{l}\text { Gibbsite, } \\
\mathbf{A l}(\mathbf{O H})_{3}{ }^{11\}}\end{array}$ & $\begin{array}{l}\text { Boehmite, } \\
\operatorname{AlO}(\mathrm{OH})^{[2]}\end{array}$ & $\begin{array}{c}\text { Kaolinite, } \\
\mathrm{Al}_{2} \mathrm{Si}_{2} \mathrm{O}_{5}(\mathbf{O H})_{4}{ }^{[3]}\end{array}$ & $\begin{array}{c}\text { Pyrophyllite, } \\
\mathrm{Al}_{2} \mathrm{Si}_{4} \mathrm{O}_{10}(\mathrm{OH})_{2}{ }^{[4]}\end{array}$ \\
\hline $\begin{array}{l}\text { ClayFF- } \\
\text { orig }\end{array}$ & - & 6.97 & 2.64 & $\underline{0.91}$ & 7.59 \\
\hline \multirow{8}{*}{$\begin{array}{l}\text { ClayFF- } \\
\text { MOH }^{[5]}\end{array}$} & 100 & 6.04 & $\underline{2.01}^{[5]}$ & 6.44 & $\underline{2.06}$ \\
\hline & 105 & 4.70 & $\underline{2.01}$ & 6.15 & $\underline{1.94}$ \\
\hline & 110 & 3.29 & $\underline{2.11}$ & 5.27 & $\underline{1.87}$ \\
\hline & 115 & $\underline{1.94}$ & $\underline{2.33}$ & 6.51 & $\underline{1.71}$ \\
\hline & $116^{[6]}$ & $\underline{1.73}$ & $\underline{2.33}$ & 3.63 & $\underline{1.69}$ \\
\hline & 120 & $\underline{2.12}$ & $\underline{2.48}$ & $\underline{1.46}$ & 11.19 \\
\hline & 125 & 3.67 & 2.75 & $\underline{1.21}$ & 20.90 \\
\hline & 130 & 5.47 & 3.12 & $\underline{1.16}$ & 10.90 \\
\hline
\end{tabular}

${ }^{[1]}$ Ref. 64

${ }^{[2]}$ Ref. 65.

${ }^{[3]}$ Ref. 46.

${ }^{[4]}$ Ref. 66.

${ }^{[5]}$ Errors inferior to $2.5 \%$ are underlined.

${ }^{[6]}$ This particular $\theta_{0, \mathrm{AlOH}}$ value is included because it was mentioned in our previous work. ${ }^{39}$ 
We note that a more complete study should involve a smaller sampling mesh and include the dependence of the lattice parameters on the force constant $k_{\mathrm{AlOH}}$. However, we can see from Table 4 that, with the exception of kaolinite, at $k_{\mathrm{AlOH}}=15 \mathrm{kcal} \cdot \mathrm{mol}^{-1} \cdot \mathrm{rad}^{-2} \mathrm{a} \theta_{0}$ value can always be found which improves the bulk crystal lattice parameters relative to ClayFF-orig. Even for pyrophyllite, where hydrogen bonding is not involved in keeping the layers together, the M-O-H angle bending term affects lattice parameters. In this case, the change in orientation of the intralayer hydroxyl groups is sufficient to slightly distort the siloxane network and, indirectly, cause a modification of the layer-to-layer interaction.

\section{Vibrational spectra}

It is known that the $\mathrm{Si}-\mathrm{O}-\mathrm{H}$ bending vibrations are sensitive to differences of structure and composition of surface hydroxyl groups in materials like silica or zeolites, and can be used to quantitative characterization of their surface properties (see, e.g., Ref. 67). We have calculated the vibrational density of states for the $\mathrm{Si}-\mathrm{OH}$ groups at the kaolinite edge surfaces from the velocity autocorrelation function $f(t)$ of the corresponding hydrogen atoms. The function $f^{\prime}(t)$ is further obtained by windowing $f(t)$, with the upper bound set to $t_{\text {win }}=1$ ps:

$$
f^{\prime}(t)=f(t) \sqrt{1-\frac{t}{t_{\text {win }}}}
$$

The vibrational density of states $P(v)$ is then calculated as:

$$
P(v)=\int\left[\left(f^{\prime}(t) \cos (\omega t)\right)^{2}+\left(f^{\prime}(t) \sin (\omega t)\right)^{2}\right] d t
$$

The vibrational power spectra were derived for $\mathrm{H}$ atoms of $\mathrm{Si}-\mathrm{O}-\mathrm{H}$ and $\mathrm{Al}-\mathrm{O}-\mathrm{H}$ edge surface groups from MD trajectories. The most informative range of librational (bending) frequencies is shown in Figure 7 for the (010) kaolinite edges, comparing the performance of the two versions of ClayFF-MOH, ClayFF-orig, with the results of DFT-MD. As seen in the 
top panel, ClayFF-MOH predicts slightly lower frequencies than DFT-MD for the librational modes of $\mathrm{Si}-\mathrm{O}-\mathrm{H}$ and $\mathrm{Al}-\mathrm{O}-\mathrm{H}$ at higher wavenumbers, while these modes are completely missing with ClayFF-orig. After resolving the spectra into in-plane and out-of-plane motion with respect to the equilibrium Si-O-H plane (middle and lower panels, respectively), these higher frequency modes are clearly due to the in-plane Si-O-H bending. At the same time, the librational modes at lower frequency are due to the out-of-plane Si-O-H vibrations, and are accurately predicted by ClayFF with or without the M-O-H angle bending terms. These modes are generally controlled by $\mathrm{H}$-bonding with neighboring surface $\mathrm{O}-\mathrm{H}$ groups or water molecules.

\section{$\mathrm{AC}_{1}$}

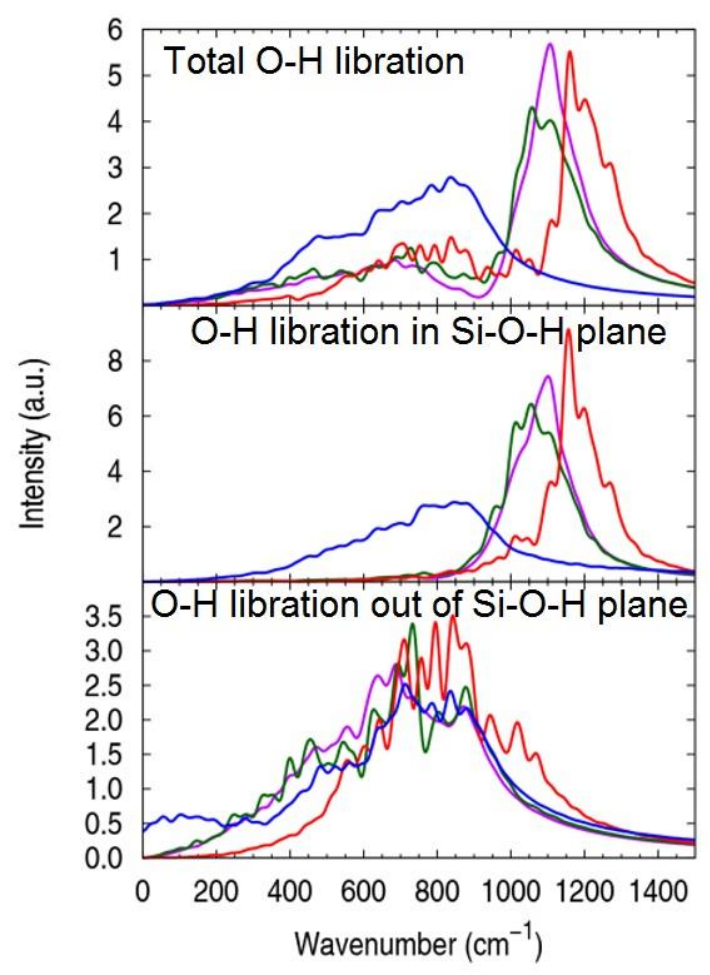

$\mathrm{AC}_{2}$

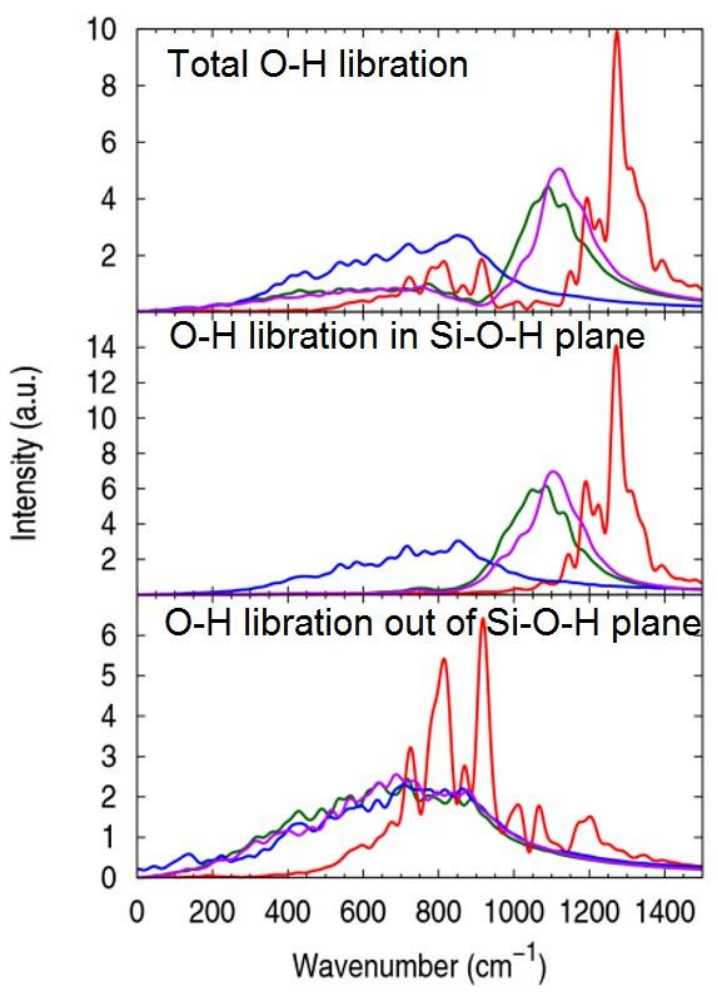

Figure 7. Hydrogen power spectra of the $\mathrm{OH}$ groups of the kaolinite $\mathrm{AC}_{1}$ and $\mathrm{AC}_{2}$ edge surfaces in the $\mathrm{O}-\mathrm{H}$ libration region. Color coding of the curves is the same as in Figs. 4,6. 
A detailed analysis of the vibrational behavior of the edge surface hydroxyl groups of kaolinite, including a comparison with available experimental vibrational spectra, are beyond the scope of the current work and will be discussed elsewhere. However, the CMD results presented in Fig. 7 based on the comparison with DFT-MD calculations clearly demonstrate a great improvement brought by the addition of the $\mathrm{Si}-\mathrm{O}-\mathrm{H}$ and $\mathrm{Al}-\mathrm{O}-\mathrm{H}$ bending terms for reproducing the librational spectra of the edge O-H groups.

\section{Selection of the Si-O-H parameters}

The overall better performance of $\left\{\theta_{0, S_{S O H}}=100^{\circ}, k_{S i O H}=15 \mathrm{kcal} \cdot \mathrm{mol}^{-1} \mathrm{rad}^{-2}\right\}$ in terms of structural properties of the kaolinite surfaces makes it a better choice than $\left\{\theta_{0, S i O H}=110^{\circ}\right.$, $\left.k_{S i O H}=15 \mathrm{kcal} \cdot \mathrm{mol}^{-1} \cdot \mathrm{rad}^{-2}\right\}$. One could argue from the maps of the mean structural differences (Figure 2) that a decrease in the $\theta_{0, \mathrm{SiOH}}$ value from $110^{\circ}$ to $100^{\circ}$ should be accompanied by a decrease in the $k$ value from $15 \mathrm{kcal} \cdot \mathrm{mol}^{-1} \cdot \mathrm{rad}^{-2}$ to $5-10 \mathrm{kcal} \cdot \mathrm{mol}^{-1} \cdot \mathrm{rad}^{-2}$. The pair $\left\{\theta_{0, \mathrm{SiOH}}=110^{\circ}, \mathrm{kSiOH}_{\mathrm{S}}=8 \mathrm{kcal} \cdot \mathrm{mol}^{-1} \mathrm{rad}^{-2}\right\}$ was also tested in the simulations but it only resulted in small structural deviations with respect to $\left\{\theta_{0, S i O H}=110^{\circ}, k_{S i O H}=15 \mathrm{kcal} \cdot \mathrm{mol}^{-1} \cdot \mathrm{rad}^{-2}\right\}$, and it worsened the performance in terms of vibrational spectra, shifting the spectra towards lower wavenumbers, as should be expected.

\section{CONCLUSIONS}

Combined with the $\mathrm{Al}-\mathrm{O}-\mathrm{H}$ and $\mathrm{Mg}-\mathrm{O}-\mathrm{H}$ angle bending terms from our previous work, ${ }^{38,39}$ present results for the angle bending terms of tetrahedral Si-O-H groups at aluminosilicate edges have been collected in the new ClayFF-MOH parametrization (Table 5). This new functionality enables the simulation of a wide variety of edge-fluid interfaces while maintaining the same degree of lattice flexibility inherent in ClayFF. Additional adjustments 
may be required for other octahedral or tetrahedral ions such $\mathrm{Fe}, \mathrm{Al}$, etc., or for deprotonated sites $\left(\mathrm{AlO}^{-}\right.$or $\left.\mathrm{SiO}^{-}\right)$, but such effort will require spectroscopic results for guidance.

Table 5. Metal-O-H angle bending term parameters of the modified ClayFF-MOH force field.

\begin{tabular}{lcc}
\hline Angle & $\begin{array}{c}\boldsymbol{k} \\
\left(\mathbf{k c a l} \cdot \mathbf{~ m o l}^{-\mathbf{1}} \cdot \mathbf{r a d}^{-\mathbf{2}}\right)\end{array}$ & $\boldsymbol{\theta}_{0}\left(^{\circ}\right)$ \\
ao-oh-ho, bulk & 15 & 116 \\
ao-oh-ho, surface & 15 & 110 \\
mg-oh-ho, bulk & 6 & 120 \\
mg-oh-ho, surface & 6 & 110 \\
st-oh-ho & 15 & 100 \\
\hline
\end{tabular}

Table 5 also includes slight adjustments in the octahedral M-O-H equilibrium angle for distinguishing the bulk or surface hydroxyl groups. Additional fine-tuning of angle bending parameters may also be needed to better describe vibrational properties for specific interfaces, and may be needed for accurate modeling of local structure at edges or at other silicate surfaces. But for large-scale simulations of clay edges at fluid interfaces, subtle adjustment of M-O-H angle bending parameters will likely have little effect on interfacial properties (e.g., adsorption, diffusion) at longer time and larger length scales. In those cases, the angle bending terms in ClayFF-MOH serve to tether the hydroxyl groups to the edge surfaces, thereby preventing dissociation of these groups which is beyond the practical scope of a non-reactive force field like ClayFF. Likewise, simulations involving confined shear should be possible with ClayFFMOH under mild conditions (i.e., elastic regime).

Note that recent kaolinite edge simulations ${ }^{10}$ have already demonstrated that inclusion of Si-O-H angle bending parameters, even when unoptimized by comparison with DFT results, allows edge surfaces to be simulated efficiently. The optimized ClayFF-MOH (Table 5) should 
now be suitable for modeling hydroxylated edge or basal surfaces of clays, related layered minerals, and other aluminosilicate phases. Our goal in developing ClayFF-compatible M-O-H angle bending terms is to faithfully reproduce the structural properties of edge hydroxyl groups in a wide range of interfacial environments. ClayFF can then be used to simulate structural and dynamic properties at edge surfaces as it has been used to simulate basal surfaces since the publication of the original ClayFF parameters in $2004 .{ }^{29}$ Spectroscopic determinations of the librational dynamics of M-O-H groups in kaolinite and other clay phases can help evaluate the accuracy of both DFT and new ClayFF parameters, especially in the discrimination of bulk and surface occurrences.

\section{ACKNOWLEDGMENTS}

This work was supported by the industrial chair "Storage and Disposal of Radioactive Waste" at the Institut Mines-Télécom Atlantique, funded by ANDRA, Orano, and EDF (A.G.K. and M.P.), and by the U.S. Department of Energy, Office of Science, Office of Basic Energy Sciences, Chemical Sciences, Geosciences, and Biosciences Division (J.A.G. and R.T.C.). A.G.K. also acknowledges the financial support of the European Union's Horizon 2020 research and innovation program under grant agreements No. 640979 and 764810. Generous allocations of supercomputing resources at the CCIPL, GENCI and TGCC supercomputing facilities (projects x2014096921, x2015096921, t2016096921, and A0020906921) are also most gratefully acknowledged. Sandia National Laboratories is a multimission laboratory managed and operated by National Technology and Engineering Solutions of Sandia, LLC., a wholly owned subsidiary of Honeywell International, Inc., for the U.S. Department of Energy's National Nuclear Security Administration under contract DE-NA0003525. The views expressed in this article do not necessarily represent the views of the U.S. Department of Energy or the United States Government. 


\section{References}

(1) Geysermans, P.; Noguera, C. Advances in Atomistic Simulations of Mineral Surfaces. Journal of Materials Chemistry 2009, 19, 7807-7821.

(2) Greathouse, J.A.; Johnson, K.L.; Greenwell, H.C. Interaction of Natural Organic Matter with Layered Minerals: Recent Developments in Computational Methods at the Nanoscale. Minerals 2014, 4, 519-540.

(3) Heinz, H.; Ramezani-Dakhel, H. Simulations of Inorganic-Bioorganic Interfaces to Discover New Materials: Insights, Comparisons to Experiment, Challenges, and Opportunities. Chemical Society Reviews 2016, 45, 412-448.

(4) Kirkpatrick, R.J.; Kalinichev, A.G.; Bowers, G.M.; Yazaydin, A.O.; Krishnan, M.; Saharay, M.; Morrow, C.P. NMR and Computational Molecular Modeling Studies of Mineral Surfaces and Interlayer Galleries: A Review. Am. Mineral. 2015, 100, 13411354.

(5) Martins, M.L.; Gates, W.P.; Michot, L.; Ferrage, E.; Marry, V.; Bordallo, H.N. Neutron Scattering, a Powerful Tool to Study Clay Minerals. Appl. Clay Sci. 2014, 96, 22-35.

(6) Skipper, N.T.; Lock, P.A.; Titiloye, J.O.; Swenson, J.; Mirza, Z.A.; Howells, W.S.; Fernandez-Alonso, F. The Structure and Dynamics of 2-Dimensional Fluids in Swelling Clays. Chemical Geology 2006, 230, 182-196.

(7) Sutton, R.; Sposito, G. Molecular Simulation of Humic Substance-Ca-Montmorillonite Complexes. Geochim. Cosmochim. Acta 2006, 70, 3566-3581.

(8) Anderson, R.L.; Ratcliffe, I.; Greenwell, H.C.; Williams, P.A.; Cliffe, S.; Coveney, P.V. Clay Swelling - A Challenge in the Oilfield. Earth-Science Reviews 2010, 98, 201-216.

(9) Greathouse, J.A.; Cygan, R.T.; Fredrich, J.T.; Jerauld, G.R. Adsorption of Aqueous Crude Oil Components on the Basal Surfaces of Clay Minerals: Molecular Simulations Including Salinity and Temperature Effects. J. Phys. Chem. C 2017, 121, 22773-22786. 
(10) Zeitler, T.R.; Greathouse, J.A.; Cygan, R.T.; Fredrich, J.T.; Jerauld, G.R. Molecular Dynamics Simulation of Resin Adsorption at Kaolinite Edge Sites: Effect of Surface Deprotonation on Interfacial Structure. J. Phys. Chem. C 2017, 121, 22787-22796.

(11) Chen, B.; Evans, J.R.G.; Greenwell, H.C.; Boulet, P.; Coveney, P.V.; Bowden, A.A.; Whiting, A. A Critical Appraisal of Polymer-Clay Nanocomposites. Chemical Society Reviews 2008, 37, 568-594.

(12) Cygan, R.T.; Greathouse, J.A.; Heinz, H.; Kalinichev, A.G. Molecular Models and Simulations of Layered Minerals. Journal of Materials Chemistry 2009, 19, 2470-2481.

(13) Scocchi, G.; Posocco, P.; Fermeglia, M.; Pricl, S. Polymer-Clay Nanocomposites: A Multiscale Molecular Modeling Approach. J. Phys. Chem. B 2007, 111, 2143-2151.

(14) Suter, J.L.; Groen, D.; Coveney, P.V. Chemically Specific Multiscale Modeling of Clay-Polymer Nanocomposites Reveals Intercalation Dynamics, Tactoid Self-Assembly and Emergent Materials Properties. Advanced Materials 2015, 27, 966-984.

(15) Suter, J. L.; Groen, D.; Coveney, P. V. Mechanism of Exfoliation and Prediction of Materials Properties of Clay-Polymer Nanocomposites from Multiscale Modeling. Nano Letters 2015, 15, 8108-8113.

(16) Zeng, Q.H.; Yu, A.B.; Lu, G.Q. Multiscale Modeling and Simulation of Polymer Nanocomposites. Progress in Polymer Science 2008, 33, 191-269.

(17) Aristilde, L.; Marichal, C.; Miehe-Brendle, J.; Lanson, B.; Charlet, L. Interactions of Oxytetracycline with a Smectite Clay: A Spectroscopic Study with Molecular Simulations. Environmental Science \& Technology 2010, 44, 7839-7845.

(18) Liu, C.; Li, H.; Johnston, C.T.; Boyd, S.A.; Teppen, B.J. Relating Clay Structural Factors to Dioxin Adsorption by Smectites: Molecular Dynamics Simulations. Soil Science Society of America Journal 2012, 76, 110-120. 
(19) Okumura, M.; Kerisit, S.; Bourg, I.C.; Lammers, L.N.; Ikeda, T.; Sassi, M.; Rosso, K.M.; Machida, M. Radiocesium Interaction with Clay Minerals: Theory and Simulation Advances Post-Fukushima. Journal of Environmental Radioactivity 2018, $189,135-145$.

(20) Zhang, C.; Liu, X.; Lu, X.; He, M.; Jan Meijer, E.; Wang, R. Surface Complexation of Heavy Metal Cations on Clay Edges: Insights from First Principles Molecular Dynamics Simulation of Ni(II). Geochim. Cosmochim. Acta 2017, 203, 54-68.

(21) Psarras, P.; Holmes, R.; Vishal, V.; Wilcox, J. Methane and $\mathrm{CO}_{2}$ Adsorption Capacities of Kerogen in the Eagle Ford Shale from Molecular Simulation. Acc. Chem. Res. 2017, $50,1818-1828$.

(22) Rotenberg, B.; Marry, V.; Dufreche, J.F.; Malikova, N.; Giffaut, E.; Turq, P. Modelling Water and Ion Diffusion in Clays: A Multiscale Approach. Comptes Rendus Chimie 2007, 10, 1108-1116.

(23) Ngouana-Wakou, B. F.; Kalinichev, A. G. Structural Arrangements of Isomorphic Substitutions in Smectites: Molecular Simulation of the Swelling Properties, Interlayer Structure, and Dynamics of Hydrated Cs-Montmorillonite Revisited with New Clay Models. J. Phys. Chem. C 2014, 118, 12758-12773.

(24) Zaunbrecher, L.K.; Cygan, R.T.; Elliott, W.C. Molecular Models of Cesium and Rubidium Adsorption on Weathered Micaceous Minerals. J. Phys. Chem. A 2015, 119, $5691-5700$.

(25) Ma, Z.; Pathegama Gamage, R.; Rathnaweera, T.; Kong, L. Review of Application of Molecular Dynamic Simulations in Geological High-Level Radioactive Waste Disposal. Applied Clay Science 2019, 168, 436-449.

(26) Arab, M.; Bougeard, D.; Smirnov, K.S. Experimental and Computer Simulation Study of the Vibrational Spectra of Vermiculite. Phys.Chem.-Chem.Phys. 2002, 4, 1957-1963. 
(27) Teppen, B.J.; Rasmussen, K.R.; Bertsch, P.M.; Miller, D.M.; Schafer, L. Molecular Dynamics Modeling of Clay Minerals. 1. Gibbsite, Kaolinite, Pyrophillite, and Beidellite. J. Phys. Chem. B 1997, 101, 1579-1587.

(28) Sainz-Diaz, C.I.; Hernandez-Laguna, A.; Dove, M.T. Modeling of Dioctahedral 2:1 Phyllosilicates by Means of Transferable Empirical Potentials. Phys. Chem. Minerals 2001, 28, 130-141.

(29) Cygan, R.T.; Liang, J.-J.; Kalinichev, A.G. Molecular Models of Hydroxide, Oxyhydroxide, and Clay Phases and the Development of a General Force Field. $J$. Phys. Chem. B 2004, 108, 1255-1266.

(30) Heinz, H.; Lin, T.J.; Mishra, R.K.; Emami, F.S. Thermodynamically Consistent Force Fields for the Assembly of Inorganic, Organic, and Biological Nanostructures: The INTERFACE Force Field. Langmuir 2013, 29, 1754-1765.

(31) Tesson, S.; Louisfrema, W.; Salanne, M.; Boutin, A.; Ferrage, E.; Rotenberg, B.; Marry, V. Classical Polarizable Force Field To Study Hydrated Charged Clays and Zeolites. J. Phys. Chem. C 2018, 122, 24690-24704.

(32) Martins, D. M. S.; Molinari, M.; Gonçalves, M. A.; Mirão, J. P.; Parker, S. C. Toward Modeling Clay Mineral Nanoparticles: The Edge Surfaces of Pyrophyllite and Their Interaction with Water. J. Phys. Chem. C 2014, 118, 27308-27317.

(33) Newton, A.G.; Sposito, G. Molecular Dynamics Simulations of Pyrophyllite Edge Surfaces: Structure, Surface Energies, and Solvent Accessibility. Clays and Clay Minerals 2015, 63, 277-289.

(34) Newton, A.G.; Kwon, K.D.; Cheong, D.K. Edge Structure of Montmorillonite from Atomistic Simulations. Minerals 2016, 6, 25. 
(35) Ho, T. A.; Greathouse, J. A.; Wang, Y.; Criscenti, L. J. Atomistic Structure of Mineral Nano-aggregates from Simulated Compaction and Dewatering. Scientific Reports 2017, $7,15286$.

(36) Churakov, S. V. Structure and Dynamics of the Water Films Confined between Edges of Pyrophyllite: A First Principle Study. Geochim. Cosmochim. Acta 2007, 71, 11301144.

(37) Lammers, L.N.; Bourg, I.C.; Okumura, M.; Kolluri, K.; Sposito, G.; Machida, M. Molecular Dynamics Simulations of Cesium Adsorption on Illite Nanoparticles. $J$. Coll. Interf. Sci. 2017, 490, 608-620.

(38) Zeitler, T.R.; Greathouse, J.A.; Gale, J.D.; Cygan, R.T. Vibrational Analysis of Brucite Surfaces and the Development of an Improved Force Field for Molecular Simulation of Interfaces. J. Phys. Chem. C 2014, 118, 7946-7953.

(39) Pouvreau, M.; Greathouse, J.A.; Cygan, R.T.; Kalinichev, A.G. Structure of Hydrated Gibbsite and Brucite Edge Surfaces: DFT Results and Further Development of the ClayFF Classical Force Field with Metal-O-H Angle Bending Terms. J. Phys. Chem. C 2017, 121, 14757-14771.

(40) Cygan, R. T.; Tazaki, K., Interactions of Kaolin Minerals in the Environment. Elements 2014, 10, 195-200.

(41) Balan, E.; Calas, G.; Bish, D. L., Kaolin-Group Minerals: From Hydrogen-Bonded Layers to Environmental Recorders. Elements 2014, 10, 183-188.

(42) Brady, P. V.; Cygan, R. T.; Nagy, K. L., Molecular Controls on Kaolinite Surface Charge. J. Coll. Interf. Sci. 1996, 183, 356-364.

(43) Kremleva, A., Krüger, S., and Rösch, N. (2011) Uranyl adsorption at (010) edge surfaces of kaolinite: A density functional study. Geochimica et Cosmochimica Acta, 75(3), 706-718. 
(44) Liu, X.D.; Lu, X.C.; Wang, R.C.; Meijer, E.J.; Zhou, H.Q.; He, H.P. Atomic Scale Structures of Interfaces between Kaolinite Edges and Water.

Geochim. Cosmochim. Acta 2012, 92, 233-242.

(45) Liu, X.D.; Lu, X.C.; Sprik, M.; Cheng, J.; Meijer, E.J.; Wang, R.C. Acidity of Edge Surface Sites of Montmorillonite and Kaolinite. Geochim. Cosmochim. Acta 2013, 117, 180-190.

(46) Neder, R. B.; Burghammer, M.; Grasl, T.; Schulz, H.; Bram, A.; Fiedler, S. Refinement of the Kaolinite Structure from Single-Crystal Synchrotron Data. Clays Clay Miner. 1999, 47, 487-494.

(47) Bish, D. L.; Rietveld refinement of the kaolinite structure at 1.5 K. Clays Clay Miner. 1993, $41,738-744$.

(48) Kameda, J.; Yamagishi, A.; Kogure, T. Morphological Characteristics of Ordered Kaolinite: Investigation Using Electron Back-Scattered Diffraction. Am. Mineral. 2005, $90,1462-1465$.

(49) White, G.; Zelazny, L. Analysis and Implications of the Edge Structure of Dioctahedral Phyllosilicates. Clays Clay Miner. 1988, 36, 141-146.

(50) Grimme, S.; Antony, J.; Ehrlich, S.; Krieg, H. A Consistent and Accurate Ab Initio Parametrization of Density Functional Dispersion Correction (DFT-D) for the 94 Elements H-Pu. J. Chem. Phys. 2010, 132, 154104.

(51) VandeVondele, J.; Krack, M.; Mohamed, F.; Parrinello, M.; Chassaing, T.; Hutter, J. Quickstep: Fast and Accurate Density Functional Calculations Using a Mixed Gaussian and Plane Waves Approach. Comput. Phys. Commun. 2005, 167, 103-128.

(52) VandeVondele, J.; Hutter, J. Gaussian Basis Sets for Accurate Calculations on Molecular Systems in Gas and Condensed Phases. J. Chem. Phys. 2007, 127, 114105. 
(53) Goedecker, S.; Teter, M.; Hutter, J. Separable Dual-Space Gaussian Pseudopotentials. Phys. Rev. B 1996, 54, 1703-1710.

(54) Greathouse, J. A.; Durkin, J. S.; Larentzos, J. P.; Cygan, R. T. Implementation of a Morse Potential to Model Hydroxyl Behavior in Phyllosilicates. J. Chem. Phys. 2009, $130,134713$.

(55) Berendsen, H. J. C.; Postma, J. P. M.; Gunsteren, W. F. van; Hermans, J. Interaction Models for Water in Relation to Protein Hydration. In Intermolecular Forces; Pullman, B., Ed.; The Jerusalem Symposia on Quantum Chemistry and Biochemistry; Springer Netherlands, 1981; pp 331-342.

(56) Teleman, O.; Jönsson, B.; Engström, S. A Molecular Dynamics Simulation of a Water Model with Intramolecular Degrees of Freedom. Mol. Phys. 1987, 60, 193-203.

(57) Gale, J. D.; Rohl, A. L. The General Utility Lattice Program (GULP). Mol. Simul. 2003, 29, 291-341.

(58) Plimpton, S. Fast Parallel Algorithms for Short-Range Molecular Dynamics. J. Comput. Phys. 1995, 117, 1-19.

(59) Martyna, G. J.; Klein, M. L.; Tuckerman, M. Nosé-Hoover Chains: The Canonical Ensemble via Continuous Dynamics. J. Chem. Phys. 1992, 97, 2635-2643.

(60) Parrinello, M.; Rahman, A. Polymorphic Transitions in Single Crystals: A New Molecular Dynamics Method. J. Appl. Phys. 1981, 52, 7182-7190.

(61) Chowdhuri, S.; Chandra, A. Hydrogen Bonds in Aqueous Electrolyte Solutions: Statistics and Dynamics Based on Both Geometric and Energetic Criteria. Phys. Rev. E 2002, 66, 041203.

(62) Kalinichev, A. G., Universality of Hydrogen Bond Distributions in Liquid and Supercritical Water. J. Mol. Liquids 2017, 241, 1038-1043. 
(63) Yu, K. A.; Schmidt, J. R., Elucidating the Crystal Face- and Hydration-Dependent Catalytic Activity of Hydrotalcites in Biodiesel Production. Journal of Physical Chemistry C 2011, 115, 1887-1898.

(64) Saalfeld, H.; Wedde, M. Refinement of Crystal-Structure of Gibbsite, $\mathrm{Al}(\mathrm{OH})_{3}$. Z. Krist. 1974, 139, 129-135.

(65) Corbato, C. E.; Tettenhorst, R. T.; Christoph, G. G. Structure Refinement of Deuterated Boehmite. Clays and Clay Minerals 1985, 33, 71-75.

(66) Lee, J.; Guggenheim, S. Single-Crystal X-Ray Refinement of Pyrophyllite-1tc. Am. Mineral. 1981, 66, 350-357.

(67) Mix, H.; Sauer, J.; Schroder, K. P.; Merkel, A. Vibrational Properties of Surface Hydroxyls: Nonempirical Model-Calculations Including Anharmonicities. Collection of Czechoslovak Chemical Communications 1988, 53, 2191-2202. 
TOC graphics

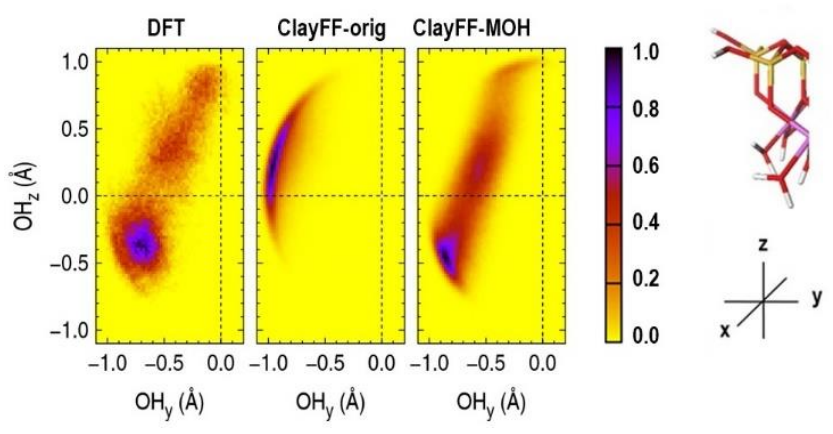

